OXMAN, Nicolás. "La incapacidad para oponerse en los delitos de violación y abusos sexuales".

Polít. crim. Vol. 10, № 19 (Julio 2015), Art. 4, pp. 92-118.

[http://www.politicacriminal.cl/Vol_10/n_19/Vol10N19A4.pdf]

\title{
La incapacidad para oponerse en los delitos de violación y abusos sexuales*
}

The inability to resist in the crimes of rape and sexual abuse

\author{
Nicolás Oxman \\ Profesor de Derecho Penal \\ Universidad Santo Tomás (Chile) \\ nicolasoxman@santotomas.cl
}

\section{Resumen}

Este trabajo es sobre el concepto, estructura y límites de la incapacidad de oponerse en los delitos de violación y abusos sexuales. En especial, acerca de la posibilidad de extender la aplicación de la norma a la disminución de posibilidades psíquicas de respuesta, concretamente, a las relaciones sexuales no consentidas en contextos de intoxicación por consumo de drogas o alcohol, o bien, en casos de sueño profundo. Finalmente, trata sobre la validez del consentimiento sexual prestado por adultos con trastornos mentales no constitutivos de enajenación o que padecen el "síndrome de la persona abusada".

Palabras clave: Incapacidad de resistir, actos sexuales no consentidos, violación, abusos sexuales.

\begin{abstract}
This article focuses on the conceptual structure, scope and limits of incapable resistance in rape and sexual abuse. Specially, about the possibility of extending the application of the rule to a decrease in psychic response abilities, specifically, in no-consensual sexual intercourse within contexts of drugs and alcohol intoxication, or, in cases of deep sleep. Finally it aims at signaling specific concerns regarding the validity of consent given by adults with mental disorders that do not constitute insanity or suffering from "battered person syndrome".
\end{abstract}

Key words: Inability to resist, non-consensual sexual intercourse, rape, sexual abuse.

\section{Autodeterminación sexual como contexto de valoración.}

Un punto en el que con una relativa equivalencia en cuanto a sus fundamentos están de acuerdo los ordenamientos penales occidentales, es que deben adquirir significación jurídico-penal las acciones que puedan ser objetivamente interpretadas como una constricción de la libertad e integridad personal en el plano de las relaciones sexuales entre 


\section{Polít. crim. Vol. 10, Nº 19 (Julio 2015), Art. 4, pp. 92-118. [http://www.politicacriminal.cl/Vol_10/n_19/Vol10N19A4.pdf]}

personas adultas ${ }^{1}$. Más allá que se pueda discutir sobre cuál o cuáles son o deberían ser los intereses, derechos o bienes que se protegen aquí ${ }^{2}$, o bien, si es necesario establecer una diferencia entre éstos y los que sirven para dar contenido conceptual al derecho penal sexual de menores ${ }^{3}$, está más o menos aceptado que la ley penal debe prohibir las acciones que importen una limitación o anulación coaccionada de la capacidad de decisión de las personas a las que la ley les reconoce plena autonomía vital para el desarrollo de su sexualidad $^{4}$.

* Este trabajo es el resultado del proyecto investigación sobre "consideraciones dogmáticas y políticocriminales de los delitos sexuales", I+D/DIP 68/2011 de la Universidad Santo Tomás. Su conclusión ha sido posible gracias al aprovechamiento circunstancial de una estancia de investigación en el Max Planck Institut für Ausländisches und Internationales Strafrechts en Alemania, en el marco del programa de Becas Chile para doctorado en el extranjero (Universidad de Valencia).

${ }^{1}$ Solo a modo de ejemplo sobre la consagración de la libertad sexual, las reformas y contrarreformas penales en tal sentido, pueden consultarse, en especial, para el derecho penal alemán, LAUBENTHAL, Klaus, Handbuch Sexualstraftaten. Die Delikte gegen die sexuelle Selbstbestimmung. Berlin: Springer, 2012, pp. 912 y pp. 14-25. GÖSSEL, Karl-Heinz, Das neue Sexualstrafrecht. Eine systematische Darstellung für die Praxis. Berlin: De Gruyter Recht, 2005, pp. 1-9. Acerca del proceso de construcción de la libertad sexual en el actual derecho penal sexual en Italia, CADOPPI, Alberto; CANESTRARI, Stefano; MANNA, Adelmo; PAPA, Michele, Trattato di Diritto Penale. Parte Speciale, t. IX. Torino: Ed. Utet-Giuridica, 2011, pp. 3-16. En el Reino Unido, ROOK, Peter; WARD Robert, Sexual Offences. Law \& Practice. London: Ed. Sweet \& Maxwell, 2014, pp. 1-4, 18-19, 25-29. CARD, Richard, Sexual Offences: the new law. Bristol: Jordans, 2004, pp. 3-9. En relación a la evolución e involución del derecho español. DÍEZ RIPOLLÉS, José Luis, "El objeto de protección en el nuevo derecho penal sexual", Revista de Derecho Penal y Criminología, $2^{\mathrm{a}}$ época, 6 (2000), pp. 69-101. GONZÁLEZ CUSSAC, José Luis, "La contrarreforma penal de 2003: nueva y vieja política criminal", Revista Jurídica Gallega, 38 (2003) p. 16. RAMÓN RIBAS, Eduardo, "La reforma de los delitos contra la libertad e indemnidad sexual", en: ÁLVAREZ GARCÍA (coord.), Libro Homenaje a Rodríguez Ramos. Valencia: Tirant lo Blanch, 2013, pp. 849-882. Sobre la libertad sexual en Estados Unidos y su influencia en la interpretación de los estatutos, ROBINSON, Paul; CAHILL, Michael, Criminal Law. Estados Unidos: Wolters Kluwer Law \& Business, 2014, pp. 589 y ss.

${ }^{2}$ Una discusión que en Chile han desarrollado, en especial, BASCUÑÁN, Antonio, "Problemas básicos de los delitos sexuales", Revista de Derecho Universidad Austral de Chile, número especial (1997), pp. 86 y ss. COX, Juan Pablo, Los abusos sexuales, Santiago: Ed. Lexis Nexis, 2003, pp. 21-97. Para una aportación acertada desde los fundamentos del derecho y su relación con la filosofía moral, únicamente, GALLEGO, Javier, "El problema del moralismo legal en el Derecho Penal", Revista de Estudios de la Justicia, 14 (2011), pp. 153-198.

${ }^{3}$ La tendencia actual es la distinción entre un derecho penal sexual para los adultos y otro para los menores, con diferentes criterios de imputación e interpretación teleológica. Así, se distingue entre los delitos contra la libertad sexual (sexuelle Freheit) de los delitos contra el desarrollo de la sexualidad (sexuelle Entwicklung) o libertad sexual en formación. LAUBENTHAL, Handbuch, cit. nota no 1, pp. 55-124 y 169 y ss. El Proyecto de Código Penal chileno de 2014 se decanta correctamente por esta opción, al consagrar en los delitos contra la libertad sexual (título III del libro Segundo) un $\$ 3$ especialmente dedicado a los atentados contra menores de los cometidos contra personas adultas, en los art. 261 y ss. (Mensaje $n^{\circ}$ 435-361, de 10.04.2014, que contemplaba el Proyecto de Ley de Nuevo Código Penal).

${ }^{4}$ La discusión sobre el contenido y significado de las conductas sexuales cometidas en contra de personas adultas, originalmente ligada a una limitación del derecho a decidir (ejercicio positivo de la libertad sexual), se ha dado paso a la protección de la capacidad plena o no disminuida de repeler acciones sexuales no consentidas (ejercicio negativo). Sin perjuicio de ello, todavía se mantienen algunos resabios de tutela de la moral sexual colectiva en lo que al derecho penal sexual de adultos se refiere, con independencia de la virtualidad que de lege ferenda o lege data se le atribuya a la libertad sexual en cada ordenamiento. Así, por ejemplo, ocurre con la punición de actividades sexuales consensuadas entre hermanos (incesto) en Alemania, conforme al §173(2) del StGB y a su declaración de constitucionalidad reciente. BVerfGe 120, 224-248, NJWNeu Juristische Wochenschrift, 4 (2013), pp. 215 y ss. AAVV. Inzestverbot. Berlin: Deutscher Ethikrat, 2014, pp. 50 y ss. Lo mismo ocurre, en el derecho chileno con la sodomía y la reciente sentencia del Tribunal 
OXMAN, Nicolás. "La incapacidad para oponerse en los delitos de violación y abusos sexuales".

De ahí, entonces, que la discusión sobre qué se protege por estas normas debería ceder frente a la utilidad que prestan en el mantenimiento de condiciones mínimas de convivencia social, al mismo tiempo que una vez aceptada la necesidad de una regulación penal para un ámbito que constituye el núcleo de los derechos relativos a la personalidad, habría que preguntarse qué implicancia tiene tal reconocimiento para la tutela de la capacidad de autodeterminación sexual $\mathrm{y}$, en concreto, para una aplicación coherente de tales presupuestos en la teoría de la imputación de los delitos de violación y abusos sexuales ${ }^{5}$.

A partir de esta aproximación, el presente trabajo aborda la circunstancia de comisión prevista en el numeral $2^{\circ}$ del art. 361 del Código Penal (en adelante, CP), denominada desde la reforma que ha tenido lugar con ley $\mathrm{n}^{\mathrm{o}} 20.480$, de 18.12.2010, como "incapacidad para oponerse", en substitución de la antigua redacción del CP que aludía a la "incapacidad de resistir". Se trata, entonces, sobre el contenido y límites de un medio que es aplicable a los tipos penales de los delitos de violación (art. 361), abusos sexuales simples (art. 366 inc. $1^{\circ}$ ) y calificados (art. 365 bis), todas figuras referidas a la libertad de autodeterminación de personas a quienes la ley protege en el ejercicio de facultades vinculadas al ejercicio privado de la sexualidad.

\section{Incapacidad de resistir e incapacidad para oponerse.}

La voluntad del legislador expresada en el debate parlamentario que tuvo lugar en la tramitación de la citada ley $\mathrm{n}^{\mathrm{o}} 20.480^{6}$, reflejada en el cambio legislativo objeto del presente estudio, fue la superación de la interpretación doctrinal mayoritaria, según la cual la incapacidad de resistir estaba condicionada al padecimiento por parte del sujeto pasivo de impedimentos físicos, temporales o permanentes que limitasen de un modo absoluto las posibilidades de hacer frente a una agresión sexual ${ }^{7}$. Tal como ocurre, por ejemplo, en el

Constitucional. Al respecto, BASCUÑÁN, Antonio, "La prohibición penal de la homosexualidad masculina juvenil (comentario a la Sentencia del Tribunal Constitucional, 04.01. 2011, rol n 163-2010)", Estudios Públicos, 124 (2011), pp. 114-136.

5 En efecto, en la actualidad el análisis de las normas penales del derecho penal sexual de adultos está enfocado a la valoración de la relación presencia-ausencia de consentimiento, cuestión que tiene trascendencia para determinar no solo la relevancia típica del comportamiento, sino que, también, en una reorientación hacia la valoración -al menos en un primer momento- puramente objetiva de la acciones realizadas por el sujeto activo, en cuanto prohibición de involucrar a otro en un contexto sexual sin su consentimiento. Para un comentario detallado de esta evolución valorativa en la jurisprudencia de Estados Unidos y Alemania, DUBBER, Markus; HÖRNLE, Tatjna, Criminal Law. A Comparative Approach, Oxford: Oxford University Press, 2014, pp. 614- 618.

${ }^{6}$ Véase, Historia de la Ley $\mathrm{N}^{\mathrm{o}}$ 20.480, Biblioteca del Congreso Nacional de Chile, pp. 346-348. Disponible en: http://www.ben.cl/obtienearchivo?id=recursoslegales/10221.3/27994/1/HL20480.pdf [consultado el 09.09.2014].

${ }^{7}$ Así, la doctrina con el texto anterior a la citada reforma, afirmaba que "la causal debe interpretarse como aplicable solo a las situaciones de imposibilidad física de oponer resistencia o para manifestar la voluntad contraria frente a la agresión". MALDONADO, Francisco, "Delitos contra la libertad sexual. Tratamiento de la nueva regulación de los delitos sexuales", en: AAVV., Problemas Actuales del Derecho Penal. Temuco: Universidad de Temuco, 2003, p. 250. En el mismo sentido, RODRÍGUEZ COLLAO, Luis, Delitos sexuales, Santiago: Ed. Jurídica de Chile, 2004, p. 156. POLITOFF, Sergio; MATUS, Jean Pierre; RAMÍREZ, M ${ }^{\text {a }}$ Cecilia, Lecciones de Derecho Penal. Parte Especial, Santiago: Ed. Jurídica de Chile, $2^{\mathrm{a}}$ ed., 2005, pp. 258259. GUZMÁN DALBORA, José Luis, "Apreciación y Reprobación de los delitos contra la honestidad en 
caso de personas que sufren de tetraplejia o se hallen atadas en un árbol ${ }^{8}$. Al mismo tiempo, la reforma ha pretendido extender, correctamente, la aplicación de la norma con el objetivo de incluir aquí supuestos en los que el sujeto activo se aprovecha no solo de la inferioridad física de otro sino que, también, cuando se abusa de una disminución de las capacidades psíquicas en la que se encuentra el sujeto pasivo. Se trata de acciones de significación sexual no precedidas de violencia, intimidación o resistencia expresa, que pese a no ser en estricto sentido una constricción coactiva de la libertad sexual de otro, deben ser interpretadas como hechos valorativamente equiparables, en cuanto suponen igualmente una limitación a la capacidad de decisión que en el plano sexual se les reconoce a las personas mayores de catorce años ${ }^{9}$.

En contra de una tesis que se había anticipado incluso con el texto anterior a la reforma ${ }^{10} \mathrm{y}$, que ahora se ha convertido en doctrina mayoritaria ${ }^{11}$, existe un grupo de autores que junto con mantener una interpretación restrictiva que evade la utilidad de la modificación normativa (incapacidad de resistir por incapacidad para oponerse), persiste en una reducción sistemática difícil de sostener que limita la aplicación fenomenológica del medio de comisión al aprovechamiento por parte del sujeto activo de impedimentos de orden físico $^{12}$. Es decir, a modalidades de incapacidad corporal (originadas en padecimientos permanentes o temporales, absolutos o relativos) que tienen una larga data de reconocimiento en el derecho comparado, en cuanto constituyen supuestos de común e

Chile", Anuario de la Facultad de Derecho de la Universidad de Antofagasta, 6 (2000), pp. 127-172, en especial, el texto correspondiente a la nota 42, p. 16.

${ }^{8}$ Este ejemplo en MALDONADO, "Delitos", cit. nota n 7 , p. 250.

${ }^{9}$ La equiparación ocurre a nivel normativo, es decir, que acciones que no son coercitivas pueden ser interpretadas como tales, porque socialmente significan una limitación de la facultad de decidir idéntica a las agresiones coactivas. SCHULHOFER, Stephen, "Taking Sexual Autonomy Seriously: Rape Law and Beyond", Law and Philosophy, 11 (1992), p. 36.

${ }^{10}$ OXMAN, Nicolás, Libertad Sexual y Estado de Derecho en Chile. Las fronteras del Derecho Penal sexual. Santiago: Librotecnia, 2007, pp. 144-146. Había insinuado la posibilidad con el texto original, en el sentido de incapacidad psíquica para manifestar una voluntad contraria al rechazo. GARRIDO MONTT, Mario, Derecho Penal. Parte especial, t. III, Santiago: Ed. Jurídica de Chile, $4^{\text {a }}$ ed. 2010, p. 286.

${ }^{11}$ Incluyendo a partir de la reforma el llamado abuso sexual por sorpresa y, también, la "imposibilidad psicológica de la víctima para oponerse a la violación", como supuestos en que se da el síndrome de acomodación en el abuso sexual". SANTIBÁÑEZ, Magdalena; VARGAS, Tatiana, "Reflexiones en torno a las modificaciones para sancionar el femicidio y otras reformas relacionadas (Ley 20.480)", Revista Chilena de Derecho, 38; 1 (2011), p. 203 (el destacado es nuestro). SANTIBÁÑEZ, Magdalena, "Delimitación de la modalidad típica de aprovechamiento de la incapacidad para oponerse en el delito de violación ", Doctrina y Jurisprudencia Penal, Universidad de los Andes, 15 (2013), pp. 43-60. AGUILAR, Cristian, Delitos sexuales. Tráfico ilícito de migrantes y trata de personas con fines de prostitución y explotación. Grooming, doctrina y jurisprudencia. Santiago: Ed. Metropolitana, $2^{\mathrm{a}}$ ed., 2012, pp. 37-38. En igual sentido, otorgan significancia a la modificación legal e incluyen también posibilidades de disminución de facultades psicológicas para expresar una voluntad contraria, BALMACEDA, Gustavo, Manual de Derecho Penal. Parte especial. Santiago: Ed. Librotecnia, 2014, p. 219. MATUS, Jean Pierre; RAMÍREZ, María Cecilia, Lecciones de Derecho Penal chileno. Parte especial, t. I. Santiago: Ed. Legal Publishing-Thomson Reuters, $3^{\text {a }}$ ed., 2014, p. 323.

${ }^{12}$ Así, ahora únicamente, RODRÍGUEZ COLLAO, Luis, Delitos sexuales. Santiago: Ed. Jurídica de Chile, $2^{\text {a }}$ ed. 2014, p. 201. Aunque con matices, BULLEMORE, Vivian; MACKINNON, John, Curso de Derecho Penal. Parte Especial, t. III, Ed. Legal Publishing, $3^{\text {a }}$ ed., Santiago, 2011, p.156. 
OXMAN, Nicolás. "La incapacidad para oponerse en los delitos de violación y abusos sexuales".

indiscutible aplicación no solo de esta forma de comisión, sino que como una hipótesis más de la fuerza propia de las agresiones sexuales ${ }^{13}$.

Es más, algunos de los casos planteados por la doctrina como el ejemplo del tercero que se aprovecha de una mujer que otro ha dejado atada, o bien, el del médico o enfermero que inyecta un medicamento al paciente que provoca en estado que limita su capacidad motora para repeler un ataque sexual realizado, o bien, incluso el del paciente que sufre "por sorpresa" tocamientos de un facultativo durante un examen médico, han sido calificados y deben ser entendidos como hechos no solo de obvia aplicación de la modalidad, sino también de interés puramente literario ${ }^{14}$.

Por estas razones, en varios ordenamientos jurídicos la tendencia es la prohibición de comportamientos que, por un lado, no son necesariamente constitutivos de violencia o intimidación y, por otro lado, tampoco constituyen una privación total de sentido, pero que pueden ser estimados como supuestos de no-consentimiento (non-consensual sexual

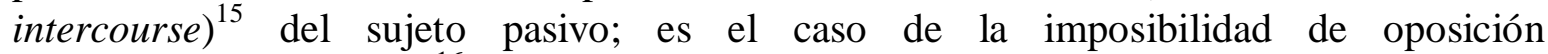
(Widerstandsunfähigkeit) ${ }^{16}$ originada en una intoxicación por drogas o alcohol. También, se

\footnotetext{
${ }^{13}$ En los sistemas anglosajones la incapacidad física de resistir se considera desde principios del siglo XX como un caso incluido dentro del concepto de fuerza, al mismo tiempo, que se regula de modo expreso la incapacidad de resistir de orden psicológico. Esa tradición se plasmó, por ejemplo, en el Reino Unido en la antigua Sexual Offences Act, 1956, Part. I, §3, §4. También, puede verse el Código Penal Modelo de Estados Unidos de 1962 (en adelante, MPC), que contempla expresamente la imposibilidad de prestar un consentimiento válido en casos de disminución de facultades psicológicas, en su §213.1. (1) (b). AAVV., Model Penal Code. Official Draft and Explanatory Notes, The American Law Institute at Washington, D.C. Philadelphia, 1962, Washington: Ed. Library of Congress, 1985. Sobre la situación actual en Estados Unidos, ROBINSON/CAHILL, Criminal Law, cit. nota $\mathrm{n}^{\circ}$ 1, pp. 576-577. En cambio, en la tradición cultural europeocontinental, la circunstancia como medio comisivo o tipo especial de violación o abusos sexuales, ha tenido un reconocimiento tímido. Así, por ejemplo, en España la circunstancia solo apareció en el art. 598. $2^{\circ}$ del Código Penal de 1928, suprimiéndose en los siguientes textos legales. Véase, LÓPEZ BARJA DE QUIROGA, Jacobo; RODRÍGUEZ RAMOS, Luis, et al., Códigos Penales españoles. Madrid: Ed. Akal, 1988, p. 872. Durante la vigencia del anterior Código Penal (1973), un sector de la doctrina reclamaba la reincorporación de esta categoría "por su conveniencia y necesidad", en cuanto "supuesto típico de comisión distinto a la privación de razón o sentido". Así, CARMONA SALGADO, Concepción, El delito de abusos deshonestos. Barcelona: Ed. Bosch, 1981, p. 9. La situación se mantiene en el Código Penal de 1995, pero hasta cierto punto, en la medida que la disminución de posibilidades de respuesta por enfermedad, inmovilización por medios mecánicos, estados vegetativos, situación de desesperación y agotamiento, se entienden comprendidas dentro de los abusos sexuales cometidos con la circunstancia $3^{\mathrm{a}}$ del art. 180. Así, ORTS BERENGUER, Enrique, "Delitos contra la libertad e indemnidad sexuales (I)", en: VIVES ANTÓN, Tomás; GONZÁLEZ CUSSAC, José Luis; CARBONELL MATEU, Juan Carlos, et., al., Derecho penal. Parte especial. Valencia: Ed. Tirant lo Blanch, $3^{\mathrm{a}}$ ed., 2010, p. 238. En el derecho alemán el Código Penal alemán (en adelante, StGB), solo contempla esta posibilidad a partir de la $33^{\text {a }}$ Reforma al derecho penal alemán de 1997, en este caso como un tipo autónomo de abusos sexuales cometidos por incapacidad de resistir en el \$179. LAUBENTHAL, Klaus, Sexualstraftaten. Die Delikte gegen die sexuelle Selbstbestimmung. Berlin: Springer-Verlag, 2000, p. 68.

${ }^{14}$ Véase, PULITANÒ, Domenico, Diritto Penale. Parte speciale: tutela penale della persona, t. I. Torino: Ed. G. Giappicheli Editore, $2^{\mathrm{a}}$ ed., 2014, p. 270.

${ }^{15}$ Este es el nombre que recibe en el derecho anglosajón, DRESSLER, Joshua, Understanding Criminal Law. San Francisco: Ed. Lexis Nexis, 6 ${ }^{\mathrm{a}}$ ed., 2012, p. 571.

16 Para resumen sobre las tendencias doctrinales y jurisprudenciales vinculadas al $\$ 179$ del StGB. KINDHÄUSER, Urs, Strafgesetzbuch. Lehr - und Praxiskommentar, 6. Auflage. Baden-Baden: Nomos, 2015, pp. 717-718.
} 


\section{Polít. crim. Vol. 10, № 19 (Julio 2015), Art. 4, pp. 92-118. [http://www.politicacriminal.cl/Vol_10/n_19/Vol10N19A4.pdf]}

abre camino la protección penal de quien ha prestado colaboración a la realización de acciones de significación sexual con la finalidad de disminuir o evitar riesgos para su integridad corporal $^{17} \mathrm{y}$, por cierto, para el que consiente a la realización de acciones sexuales procuradas a través de un aprovechamiento, fraude o engaño sobre el contenido específico del acto sexual o las cualidades personales del sujeto activo que se han tenido por determinantes para prestar un consentimiento válido (violenza sessuale per induzione $)^{18}$.

\section{La valoración normativa del consentimiento.}

La inclusión de las posibilidades apuntadas en el apartado anterior responde a la creciente reorientación de los sistemas penales hacia el entendimiento de los delitos de violación y abuso sexuales cometidos en contra de personas jóvenes y adultas, como infracciones que se estructuran, en un primer momento, sobre la base de las modalidades de limitación y ausencia de facultades de decisión, donde la tipicidad debe ser valorada teniendo en cuenta

${ }^{17}$ El consentimiento sobrevenido no debería excluir la tipicidad del hecho. En consecuencia, son igualmente punibles las acciones sexuales que, realizadas sin un consentimiento inicial, durante su desarrollo puedan interpretarse en sentido contrario; el hecho que se experimente placer sexual, o bien, se ejecuten actos que en esa primera aproximación puedan ser entendidos como expresivos de consentimiento no implica relevancia penal si tales acciones, en un segundo momento valorativo, significaban solo una disminución del riesgo de lesiones o atentados contra la vida de que podía ser objeto quien había aparentemente consentido. Lo mismo ocurre con el consentimiento diferenciado, es decir, los casos en que una persona acepta un acto sexual con un determinado contenido, pero durante su realización sobreviene la ausencia de disenso sobre alguna actividad, si se accede a la práctica como consecuencia de la aplicación de fuerza o intimidación, el hecho es igualmente típico. En relación con el derecho español, recientemente, se ha fallado que no concurre el consentimiento de la víctima, si una vez que ha cesado la violencia inicial, esta accedió a ser penetrada por vía vaginal y a practicar una felación oral debido al miedo de sufrir un atentado grave a su integridad corporal dada la posición dominante del agresor. Sentencia del Tribunal Supremo, 25.09.2013, $\mathrm{n}^{\circ}$ recurso: 10426-2013, $\mathrm{n}^{\circ}$ resolución: 767/2013, ponente: Manuel Marchena Gómez. Esta tesis y la distinción referida, ORTS BERENGUER, Enrique; SUÁREZ-MIRA RODRÍGUEZ, Carlos, Los delitos contra la libertad e indemnidad sexuales. Valencia: Tirant lo Blanch, 2001, pp. 36-37. En el derecho italiano, es un principio aceptado que la ausencia de consentimiento en cualquier momento de una relación sexual desemboca en la tipicidad del hecho. En tal sentido, con referencias jurisprudenciales, CRESPI, Alberto; ZUCCALA, Guiseppe; FORTI, Gabrio, Commentario Breve al Codice Penale. Milán: Ed. Cedam, 12 ed., 2011, p. 2291. FIANDACA, Giovanni; MUSCO, Enzo, Diritto penale. Parte speciale, I delitti contra la persona, vol. I., t. I. Bologna: Zanichelli Editore, $5^{\text {a }}$ ed., 2013, p. 249. El Reino Unido la tutela penal de la libertad sexual decanta en el anuncio de pena para todas las conductas sexuales que en algún momento puedan entenderse como ausencia de consentimiento, es decir, se consiente a la realización de acciones sexuales con contenido específico y no genérico, incluso, sin referencia alguna a medios de comisión que limiten la libertad sexual, por ello, se ha considerado que constituye violación el hecho que no se respete el acuerdo previo de eyacular fuera de la vagina. Véase, ROOK/WARD, Sexual Offences, cit. nota $n^{\circ} 1$, p. 39. En el derecho alemán se consideran constitutiva de agresiones sexuales mediante fuerza o intimidación (conforme al §177 StGB), la situación en la que la víctima no presta oposición a la realización de actos sexuales como consecuencia de haber sufrido, en otro contexto, agresiones físicas proferidas por el autor, el BGH estima que en estos casos no pueden ser estimados como un consentimiento, porque lo que ha ocurrido es que la "violencia se ha transformado en intimidación", incluso si existe una separación de meses o años entre las referidas agresiones físicas y el contacto sexual, porque la violencia "sigue siendo eficaz para producir en la víctima un temor a oponerse". BGH, 17.4.2007, NStZ - Neue Zeitschrift für Strafrecht (2007), 468. KINDHÄUSER, Strafgesetzbuch, cit. nota $\mathrm{n}^{\circ} 16$, p. 714 .

${ }^{18}$ Así, en Italia, conforme a la redacción actual del art. 609-bis 2 del Código Penal. PULITANÒ, Diritto Penale, cit. nota $\mathrm{n}^{\circ}$ 14, p. 269. 
OXMAN, Nicolás. "La incapacidad para oponerse en los delitos de violación y abusos sexuales".

las posibilidades que desde un punto de vista ex-ante le asistían a uno de los intervinientes de estar realizando conductas sexuales sin el consentimiento del otro; y, en segundo momento, sobre la consideración del comportamiento sexual concreto que surge como una consecuencia del valerse de un medio de comisión que ha servido para involucrar a otro en un contexto que lesiona su autodeterminación sexual ${ }^{19}$.

Al respecto, resulta evidente el contraste con la situación existente en Chile, donde desde fines del siglo pasado, se ha insistido en dos pretensiones sui generis que fundamentan el sistema sobre la base de una distinción entre, por una parte, la naturaleza de la conducta sexual realizada (abuso o violación) y, por otra parte, en una curiosa delimitación de los medios de comisión que decanta en una tripartición subdiferenciada entre adultos, jóvenes y menores, con edades y medios de realización específicos. El resultado es una regulación caótica, en la medida en que no todos los supuestos de relaciones sexuales sin consentimiento (en especial, los casos aprovechamiento de situaciones de inferioridad o disminución de las capacidades de oposición) son aplicables a las personas adultas; en contraste con la idea actual donde prima un sistema que tiende a la bipartición (un derecho penal sexual para menores y otro común para los jóvenes y adultos), con medios de comisión abiertos y con una equiparación del desvalor de las agresiones sexuales, desterrando de la ley penal los anacrónicos nomen iuiris de violación, estupro y abusos sexuales, en la medida que tales denominaciones insisten en poner el acento en el contenido de la conducta sexual más que en la intensidad de afectación del derecho a decidir libremente en este plano ${ }^{20}$.

En efecto, en el contexto de la teoría de la imputación de los delitos contra la libertad sexual, el criterio normativo para fijar la relevancia jurídico-penal de la acción realizada no está puesto en el contenido sexual específico del acto, sino en el entendimiento de estas normas como la prohibición de involucrar a otro en un contexto sexual sin su consentimiento $\mathrm{y}$, al mismo tiempo, en la exclusión de toda valoración referida a la conducta de la víctima, en especial, sobre su pasado u orientación sexual, en la medida que aquí únicamente importa el deber que le asistía al autor conforme a las circunstancias concretas de preguntarse al menos sobre la posibilidad cierta de estar ejecutando un hecho limitando o restringiendo la libertad sexual de otro ${ }^{21}$.

\footnotetext{
${ }^{19}$ Así ocurre por influencia del MPC en legislación de Estados Unidos. ROBINSON/CAHILL, Criminal Law, cit. nota $\mathrm{n}^{\circ} 1$, p. 583 y ss. Esta orientación valorativa se ha impuesto en la mayoría del derecho anglosajón y, por cierto, en el derecho penal alemán. DUBBER/HÖRNLE, Criminal Law, cit. nota nº 5, pp. 617-618. Sobre el caso de Italia, CRESPI/ZUCCALA/FORTI, Commentario, cit. nota ${ }^{\circ}{ }^{17}$. En Alemania, LAUBENTHAL, Handbuch, cit. nota $\mathrm{n}^{\circ}$ 1, p. 124. El derecho español ha sido uno de los primeros ordenamientos del civil law en asumir esta orientación. Sobre los orígenes de la misma, por todos, ORTS BERENGUER, Enrique, Delitos contra la libertad sexual. Valencia: Ed. Tirant lo Blanch, 1995, pp. 32 y ss.

${ }^{20}$ Así, por ejemplo, el Código Penal italiano desde la reforma que ha tenido lugar en virtud de la ley de 15. 02.1996, $\mathrm{n}^{\circ}$ 66, ha unificado en un solo precepto penal, denominado violencia sexual (art. 609 bis), las conductas que anteriormente eran comprensivas de la violación o violencia carnal (ex art. 519) y abusos sexuales o actos de libídine violentos (ex art. 521). Al respecto, FIANDACA/MUSCO, Diritto penale. cit. nota $\mathrm{n}^{\circ} 17$, p. 237

${ }^{21}$ De este modo, el sistema de análisis se estructura en el siguiente orden: un medio de comisión (tipo objetivo) que es utilizado dolosamente para instrumentalizar a otro (tipo subjetivo), a fin de realizar una acción sexual específica. De ahí que, por un parte, la sola realización de un medio de comisión asumiendo el riesgo de involucrar a otro en un contexto sexual sin su voluntad, implique tentativa si no se realiza la acción
} 
Polít. crim. Vol. 10, No 19 (Julio 2015), Art. 4, pp. 92-118.

[http://www.politicacriminal.cl/Vol_10/n_19/Vol10N19A4.pdf]

Esta tesis permite una reinterpretación del contenido de los medios de comisión en los delitos de violación y abusos sexuales poniendo el acento en la prueba sobre la limitación de las facultades de decisión. Así, no se exige a prueba alguna sobre la resistencia, ni el posible consentimiento puede inferirse sobre la base de esta, porque el autor no puede pretender excusarse afirmando que la víctima no opuso resistencia alguna a la agresión ${ }^{22}$. Esto implica renunciar a la aproximación tradicional según la cual el uso de fuerza o intimidación requiere que el hecho se realice contra la voluntad del sujeto pasivo, lo que implicaría exigirle a este la realización de acciones de resistencia que suponen poner en peligro su cuerpo o la vida, porque la intensidad de la pena de la violación haría exigible una afectación particularmente intensa de las facultades de autodeterminación en el plano sexual $^{23}$. Según este punto de vista, no todos los tipos de uso de fuerza o intimidación adquieren la relevancia típica necesaria para configurar el injusto, es decir, no cualquier acometimiento material sobre el cuerpo del sujeto pasivo $\mathrm{y}$, tampoco, todas las formas de amenazas intimidatorias pueden ser consideradas objetivamente relevantes. Ahora bien, es evidente que esta pretensión de una fórmula generalizadora pierde eficacia si esa valoración objetiva se centra no solo en el específico tipo de comportamiento llevado a cabo por el sujeto activo, sino que este se pone en referencia con la forma en que en el caso concreto se ha presentado la relación ausencia-presencia de consentimiento ${ }^{24}$. A su turno, el abusar de una enajenación o trastorno mental, el aprovecharse de la incapacidad para oponerse, o bien, el acceder carnalmente a una persona que se halla privada de sentido, deben ser interpretados en el mismo sentido. Es decir, que todos estos medios de comisión describen situaciones que son utilizadas por el autor para involucrar a otro en un contexto sexual que supone una limitación o restricción significativa de su capacidad de decisión.

sexual específica y, por otra parte, que la representación de instrumentalización de otro sin su consentimiento puede excluir el dolo y constituir un error de tipo. Al respecto, en el Derecho alemán, con amplias referencias: SCHÖNKE, Adolf/SCHRÖDER, Horst, Strafgesetzbuch Kommentar, $28^{\mathrm{a}}$ Auflage. München: Verlag C.H. Beck, 2010, p. 1645 y ss.

${ }^{22}$ Debería ser suficiente con que sea posible afirmar que la víctima razonablemente tenía razones, conforme a sus circunstancias, para creer que de no someterse a los requerimientos sexuales existía un peligro de un mal grave. Así, se reconoce desde hace más de treinta años lo ha estimado la jurisprudencia de Estados Unidos desde el caso State of Maryland v. Edward Salvatore, Atlantic Reporter, 2d. 424 (1981), pp. 720 y ss. (Westlaw United States).

${ }^{23}$ Para esta tesis solo habría violación si la amenaza o la fuerza representan un gravísimo atentado a la libertad. Así, GIMBERNAT ORDEIG, Enrique, "Sobre algunos aspectos del delito de violación en el Código Penal español, con especial referencia a la violación intimidatoria", en: EL MISMO, Estudios de Derecho Penal. Madrid: Tecnos, 1990, pp. 292 y ss.

${ }^{24}$ Esto supone renunciar a la exigencia de inmediatez entre la violencia y la solicitud de realización de acciones sexuales. Así, tiene el mismo efecto la amenaza de matar a alguien mañana que la de matarle inmediatamente. Es más, son igualmente típicas a título de intimidación las agresiones físicas que se han producido en el pasado de un modo particularmente intenso y prolongado, en la medida que configuran un "estado intimidatorio" y se transforman en una amenaza constante y circunstanciada de un mal futuro. Véase, con referencia a la jurisprudencia alemana. SCHÖNKE/SCHRÖDER, Strafgesetzbuch, cit. nota $\mathrm{n}^{\circ} 21$, pp. 1645 y 1647. En relación con la última afirmación, habría que agregar que el significado concreto de afectación de la capacidad de individual de decidir, reclama una valoración personal y contextual de la gravedad de la amenaza en sede de la víctima. Este criterio, por ejemplo, lo ha asumido expresamente la justicia italiana en un caso de una extranjera que con un coeficiente intelectual que bordeaba la normalidad, en situación ilegal y de precariedad laboral y social accedió a la realización de actos sexuales sadomasoquistas por la amenaza de perder el trabajo y ser denunciada a la policía. Corte Cassazione Penale, Sezione. III, 09.06.2004, $\mathrm{n}^{\circ}$. 25727. (Wolters Kluwer Italia). 
OXMAN, Nicolás. "La incapacidad para oponerse en los delitos de violación y abusos sexuales".

La valoración normativa del consentimiento traslada la significación jurídico-penal a las posibilidades de interpretar el hecho como el quebrantamiento de la prohibición de involucrar a otro en un contexto sexual sin su voluntad, en cuanto sea posible afirmar que, conforme a las circunstancias, éste ha asumido el riesgo de una relación sexual sin consentimiento, lo que supone instrumentalizar a otro en el ejercicio de su sexualidad ${ }^{25}$.

\section{Concepto de incapacidad para oponerse.}

La incapacidad para oponerse es un medio de comisión de los delitos de violación y abusos sexuales, consistente en un aprovechamiento por parte del sujeto activo de condiciones físicas o psíquicas que disminuyen la concreta posibilidad de autodeterminación del sujeto pasivo en la esfera sexual.

El concepto que aquí se propone, se fundamenta en el entendimiento de esta modalidad de comisión como una hipótesis más de restricción o limitación del consentimiento y, por ende, se abre a la posibilidad de superar la tesis conforme a la cual la incapacidad aquí no está vinculada a la relación posibilidad-imposibilidad de otorgar un consentimiento a la realización de actos de significación sexual (como ocurriría con las modalidades de fuerza o intimidación), toda vez que estaría limitada exclusivamente al padecimiento de "algún impedimento físico que lo inhabilite para oponerse a cualquier pretensión de índole sexual que vaya contra su voluntad"26.

En el esquema sobre el que se fundamenta nuestra aproximación, esta construcción no resulta aceptable porque restringe la aplicación del tipo penal a supuestos que son obvios y, al mismo tiempo incurre en contradicciones.

En efecto, no es posible sostener que la incapacidad de resistir se diferencia de los supuestos de fuerza o intimidación porque tales modalidades sí suponen una restricción de la voluntad, mientras que la incapacidad de oponerse dependería solo de un dato externo objetivo (una disminución física de la posibilidad de respuesta), para luego decir que la misma incapacidad requiere que el acto se realice "contra la voluntad" del sujeto pasivo ${ }^{27}$. Pero, es que además este razonamiento es absolutamente incompatible con la conclusión a la que este sector doctrinal llega, según la cual el consentimiento excluye la tipicidad. Si esto es así, entonces, finalmente, se reconoce lo que se había negado, que no es otra cosa que el hecho innegable que todo el sistema de los medios de comisión de estos delitos está orientado hacia una apertura valorativa de las conductas susceptibles de ser consideradas como violación o abusos sexuales desde la exclusiva consideración de la limitación o restricción de las facultades de decisión del sujeto pasivo; no hay posibilidades sistemáticas de entender que la incapacidad de oponerse escapa a un modelo basado en el

\footnotetext{
${ }^{25}$ En Estados Unidos es suficiente a nivel subjetivo con una desconsideración o indiferencia (recklessness) frente a un riesgo evidente o manifiesto de involucrar a otro en un contexto sexual sin su consentimiento, conforme se desprende del \$213.1 MPC. Con referencias, ROBINSON/CAHILL, Criminal Law, cit. nota ${ }^{\circ}$ 1, pp. 583 y 584. Una descripción de los niveles de imputación subjetiva en el derecho anglo/americano, OXMAN, Nicolás, "Una aproximación al sistema de imputación subjetiva en el derecho penal anglosajón", Ius et Praxis, 19 (2013), pp. 169 y ss.

${ }^{26}$ RODRÍGUEZ COLLAO, Delitos, cit. nota n ${ }^{\circ}$ 12, p. 201. MALDONADO, "Delitos", cit. nota n ${ }^{\circ}$ 7, p. 250.

${ }^{27}$ RODRÍGUEZ COLLAO, Delitos, cit. nota n 12, p. 202.
} 
Polít. crim. Vol. 10, Nº 19 (Julio 2015), Art. 4, pp. 92-118.

[http://www.politicacriminal.cl/Vol_10/n_19/Vol10N19A4.pdf]

consentimiento como elemento valorativo esencial y común a todos los medios de comisión de los delitos de violación, abusos sexuales y estupro.

La comprensión de esta modalidad de comisión en el sentido apuntado se condice más el propósito del legislador quien con su inclusión pretendía abarcar casos que no necesariamente podían ser entendidos como un "atentado violento", pero que implicaban, precisamente, una limitación de la facultad de decidir y consentir, reconociendo que la amplitud de la fórmula daría lugar a cuestiones relativas a la prueba de ausencia o presencia de consentimiento ${ }^{28}$. Es más, originalmente el precepto que pretendía incluirse hablaba de "abusar de la incapacidad corporal o mental de la víctima para oponer resistencia"29, pero durante la tramitación se modificó la redacción porque parecía evidente la referencia a los dos tipos de limitaciones de facultades de decisión. Así, se transitó a la "incapacidad para oponer resistencia" y, posteriormente, a la "incapacidad de resistir", que fue la redacción definitiva $^{30}$, hasta antes de la modificación que ha tenido lugar ahora, que viene a sustituir definitivamente la idea física que es inherente a la resistencia por el amplio contenido que involucra el concepto de oposición.

En suma, tal como ocurre en otros ordenamientos jurídicos en los que se ha incluido esta modalidad, aquí se trata de regular casos en que puede existir una limitación de las facultades de respuesta u oposición del sujeto pasivo. Ahora bien, el límite sistemático está fijado aquí por el contenido conceptual de los otros medios de comisión de estos delitos. De ellos se desprende que la norma incluye, en sentido amplio, supuestos que no pueden ser interpretados objetivamente como un uso de fuerza o intimidación (primer límite) y, tampoco, constituyen una privación de sentido (segundo límite), pero que adquieren relevancia típica en la medida que el consentimiento para la realización de actos de significación sexual se ha prestado en condiciones que pueden ser entendidas como una constricción igualmente grave de la libertad de autodeterminación del otro. Así las cosas, la modalidad abarca tanto la existencia objetiva de impedimentos o padecimientos físicos corporales para prestar una oposición (incapacidad física para oponerse), como también, comprende el aprovechamiento de situaciones en las que se padece una alteración significativa de la posibilidad de percepción del mundo circundante que no alcanzan a la privación total de sentido, en cuanto este es el caso más característico de imposibilidad absoluta de oposición en el plano psíquico (incapacidad psíquica para oponerse) ${ }^{31}$.

28 Historia de la Ley $\mathrm{N}^{\mathrm{o}}$ 19.617, Biblioteca del Congreso Nacional de Chile, p. 217, disponible en: http://www.leychile.cl/Navegar?idNorma=138814 [consultado el 12.10.2014]

${ }^{29}$ Historia, cit. nota $\mathrm{n}^{\circ} 28$, p. 293.

${ }^{30}$ Historia, cit. nota ${ }^{\circ} 28$, p. 276.

31 „Körperliche - Psychische Widerstandsunfähigkeit“, son los nombres que reciben respectivamente ambas formas de incapacidad de oponerse en el derecho penal alemán. Sistema del que he tomado la distinción que se desarrolla en este trabajo. Ampliamente, LAUBENTHAL, Handbuch, cit. nota $\mathrm{n}^{\circ}$ 1, pp. 127-129. SCHÖNKE/SCHRÖDER, Strafgesetzbuch, cit. $\mathrm{n}^{\circ}$ 21, pp. 1661-1662. Aunque lo cierto es que la distinción cuenta con un desarrollo jurisprudencial y reconocimiento legal anterior en el sistema anglosajón, así en el Reino Unido de modo implícito desde la antigua Sexual Offences Act, 1956, Part. I §§1-4. Expresamente, además en el CPM de 1962 de Estados Unidos, que la contempla en el §213.1 (1) (a) - (d), lo que se reconoce en varios de los estados americanos, por ejemplo: §16-6-1 Georgia Penal Code; \$940.225 Wisconsin Penal Code; §13A-6-61 Alabama Penal Code; §130.35 New York Penal Code, etc. 
OXMAN, Nicolás. "La incapacidad para oponerse en los delitos de violación y abusos sexuales".

\section{Supuestos de incapacidad física de oposición.}

\subsection{Concepto.}

La incapacidad psíquica de oponerse comprende estados permanentes, temporales o situacionales que suponen una disminución significativa de las capacidades de físicas de respuesta corporal a estímulos sexuales donde se involucra a otro sin su consentimiento.

\section{2. Ámbito de aplicación.}

La incapacidad física de oponerse comprende tanto los supuestos de inmovilidad permanente (estados de invalidez degenerativos o patológicos, por ejemplo, una tetraplejía), como situaciones de inmovilidad temporal (como ocurre con el sujeto que se encuentra atado o encadenado a un árbol o mástil, situación que es aprovechada por otro, o bien, hallarse esposado con motivo de una detención policial e incluso estar limitado en sus facultades motoras producto de la sedación administrada por un facultativo), en las que el sujeto pasivo se halla restringido en sus capacidades motoras. En suma, se trata de impedimentos físicos permanentes o temporales que suponen estados de inmovilidad (absoluta o relativa) que restan o disminuyen significativamente las posibilidades de oposición o neutralización de acciones sexuales no consentidas ${ }^{32}$.

Dentro de esta fórmula, debe incluirse también a los denominados abusos sexuales por sorpresa $^{33}$, en la medida que se trata de acciones que restan toda capacidad de respuesta física y de previsión de medios de oposición además de ser ejecutadas en total ausencia de consentimiento. Se trata de estados situacionales de incapacidad física de oposición, cuya tipicidad queda aquí determinada por la ausencia de consentimiento como fundamento para el análisis de todas las modalidades de comisión de los delitos de violación y abusos sexuales. De otro modo, habría que considerar atípicos los acometimientos físicos inopinados que no suponen la intensidad necesaria para configurar el concepto restrictivo de incapacidad de oposición, o bien, no alcanzan a la gravedad y resistencia requeridas para entender concurrente el concepto clásico de fuerza como ocurriría, por ejemplo, en el caso del agresor que se abalanzó súbitamente sobre la espalda de una mujer, para besarle el cuello mientras tocaba sus nalgas y pechos ${ }^{34}$, o bien, en el supuesto del facultativo que durante un examen ginecológico accede carnalmente "por sorpresa" a una mujer que no pudo verle por estar tumbada sobre una camilla en posición para la práctica de un examen vaginal, detrás de una manta quirúrgica que los separaba.

En la frontera entre lo físico y lo psicológico, se sitúa la incapacidad de oposición física que se genera con un episodio de estrés postraumático que es consecuencia inmediata del

\footnotetext{
${ }^{32}$ Véase, LAUBENTHAL, Handbuch, cit. nota ${ }^{\circ}$ 1, pp. 124-125.

${ }^{33}$ Sobre el estado actual de la doctrina chilena en este punto, véase supra nota $\mathrm{n}^{\circ} 11$.

${ }^{34}$ En el derecho español, pese a la ausencia de una referencia expresa en la ley a la incapacidad para oponerse como modalidad comisiva, este caso es considerado como un supuesto evidente de abusos sexuales por ausencia de consentimiento, en la medida que el sujeto pasivo se halla en una imposibilidad física de manifestar una resistencia al abuso sexual y, por ende, se les considera abarcados por el art. 181.2 del CP español. A favor de esta interpretación, ORTS BERENGUER, "Delitos", cit. nota n 13, p. 260.
} 
Polít. crim. Vol. 10, No 19 (Julio 2015), Art. 4, pp. 92-118.

[http://www.politicacriminal.cl/Vol_10/n_19/Vol10N19A4.pdf]

padecimiento de intensas lesiones corporales, lo que produce en el sujeto pasivo un estado que anula completamente sus posibilidades tanto físicas como psicológicas de respuesta ${ }^{35}$.

Estos casos no deben suscitar mayores inconvenientes de apreciación, en contraposición a lo que puede ocurrir con los supuestos en los que se reclama el no haber prestado un consentimiento pleno, debido a la presencia de una disminución significativa de las facultades de la consciencia que no alcanza a la privación de sentido. Es decir, el debate debe centrarse en el contenido conceptual de la incapacidad psíquica de oposición, a la que se aborda en el apartado siguiente, teniendo en cuenta la sistemática de la ley, las diferencias que presenta con el Derecho comparado y, especialmente, los casos en que ha sido objeto de debate y consideración por parte de los tribunales chilenos.

\section{Supuestos de incapacidad psíquica de oposición.}

\subsection{Concepto.}

La incapacidad psíquica de oponerse comprende los estados temporales de alteración significativa de las capacidades de la consciencia, que no alcanzan a la privación total de sentido, pero que pueden ser interpretados como una indefensión expresada en la disminución de las posibilidades de autodeterminación en la esfera sexual.

\subsection{Naturaleza.}

Las situaciones de limitación de las capacidades de respuesta consciente que se abordan en las líneas que siguen son aquellas motivadas en la embriaguez, el abuso de drogas, lo que se extiende a los tratamientos médicos con depresores del sistema nervioso, el sueño profundo, algunas manifestaciones particularmente intensas del síndrome de acomodación a las agresiones sexuales $\mathrm{y}$, por último, los trastornos mentales no constitutivos de enajenación. De lo que se trata es de dilucidar en qué casos puede que el sujeto pasivo no haya tenido posibilidades reales de prestar su consentimiento pleno a la realización de actividades sexuales, porque concurrió una disminución de su capacidad de respuesta y rechazo consciente. Para el análisis de esta cuestión, ninguna relevancia típica debería tener el hecho que en alguna parte de la realización de la acción lúbrica la víctima lleve a cabo conductas que no puedan ser interpretadas como una oposición decidida, porque en la medida que el sujeto pasivo no se encuentra en condiciones plenas de decidir ni pronunciarse sobre la realización de acciones con contenido sexual, tal comportamiento nulo valor debe otorgársele en cuanto posibilidades de exclusión de la relevancia penal del

\footnotetext{
${ }^{35}$ Esto es lo que ocurrió con un mujer que producto de la aplicación masiva de fuerza o violencia por parte de dos agresores que, después de golpearla intensamente hasta que casi perdiera el conocimiento, con separación espacio-temporal, deciden violarla, "una vez que ya no podía manifestar ningún tipo de oposición a la realización del hecho, dada la contundencia de las agresiones físicas que, posteriormente, le costaron la vida". Si bien, la sentencia considera concurrentes dos medios de comisión, esto es, la fuerza y la incapacidad de resistir en la antigua redacción, no se hace cargo de los posibles problemas concursales que acarrea la referida separación temporal, en la medida que claramente se trataba de dos acciones diferentes. Sentencia Corte de Apelaciones de Teтисо, 07.12.2010, rol nº 885-2010.
} 
OXMAN, Nicolás. "La incapacidad para oponerse en los delitos de violación y abusos sexuales".

hecho $^{36}$. En efecto, la norma debe ser comprendida ahora como un supuesto de ausencia de consentimiento, lo que contrasta con la idea imperante hasta hace un tiempo, según la cual solo podrían ser punibles las acciones sexuales realizadas en ejercicio de una decidida voluntad contraria del sujeto pasivo ${ }^{37}$.

\section{3. Ámbitos de posible aplicación sistemática.}

Aunque hubiese sido suficiente con la sola referencia a la incapacidad de resistir, con una delimitación de los casos en que ella tiene lugar, incluyendo los trastornos de consciencia en sentido amplio como se hace en el Derecho comparado $^{38}$, la ley chilena efectúa una distinción entre la incapacidad de oponerse y la privación total de sentido. Al respecto, es evidente que la diferencia entre una y otra está en la intensidad de la anulación de consciencia y, es por esta razón, que el ámbito de aplicación de la incapacidad psíquica de oposición queda restringido, en un primer lugar, por la ubicación de la norma dentro del sistema de los delitos de violación y abusos sexuales.

Es por esta consideración sistemática, que la eventualidad de admitir estados de disminución de capacidades psíquicas de oposición supone excluir por lógica-normativa los casos de completa supresión de facultades intelectivo-volitivas si estos equivalen a la privación total de sentido, en cuanto supone una anulación transitoria o permanente de la consciencia. En la medida que la incapacidad psíquica de oposición y la privación total de sentido, pueden tener el mismo origen (consumo de alcohol, drogas, depresores del sistema nervioso central y sueño profundo), los límites entre ambas están dados por la valoración típica de los casos que se encuentran en la frontera que separa a la anulación total de la conciencia de la disminución significativa de la misma. En las líneas que siguen se abordan los supuestos que han sido objeto de debate en la jurisprudencia, intentando otorgar criterios normativos que permitan fundamentar o excluir su relevancia jurídico-penal como supuestos de incapacidad de oposición.

\subsection{La exigencia de aprovecharse de la incapacidad.}

Ahora bien, en alguno de los estados indicados es suficiente con la acreditación que el sujeto pasivo adolecía de una limitación significativa de la capacidad de decisión y compresión sobre el contenido de las acciones sexuales que se realizaron, situación que se decide, primordialmente, desde la prueba del aprovechamiento del sujeto activo.

\footnotetext{
${ }^{36}$ Se trata de casos donde el sujeto pasivo se encuentra en un estado de disminución de las posibilidades de valoración y apreciación consciente de su conducta. Cfr. \$231.1 CPM. ROBINSON/CAHILL, Criminal Law, cit. nota ${ }^{\circ} 1$, p. 582. Cfr. §179 (1) 1. StGB. SCHÖNKE/SCHRÖDER, Strafgesetzbuch, cit. nota $\mathrm{n}^{\circ} 21$, p. 1662.

${ }^{37}$ En efecto, en los sistemas anglosajones la ausencia de referencias a la resistencia como elemento de los medios de comisión de los delitos sexuales, en especial, en los casos de fuerza y de intimidación, con referencia a una gravedad que depende del caso concreto, es el fundamento que ha servido para reinterpretar estos delitos como supuestos de ausencia actos sexuales sin consentimiento (non-consensual sexual intercourse). Ampliamente, LAFAVE, Wayne, Criminal Law. Saint Paul: Thomson Reuters, $5^{\mathrm{a}}$ ed., 2010, pp. 905-907.

${ }^{38}$ Así en el derecho alemán se incluyen las enfermedades mentales, los estados de disminución de consciencia y los trastornos de la personalidad, incluso el llamado trastorno bipolar como la ciclotimia, por cierto, el uso de alcohol, drogas o medicamentos. LAUBENTHAL, Handbuch, cit. nota nº 1, p. 128.
} 
Polít. crim. Vol. 10, No 19 (Julio 2015), Art. 4, pp. 92-118.

[http://www.politicacriminal.cl/Vol_10/n_19/Vol10N19A4.pdf]

Al respecto, la expresión "cuando se aprovecha" que utiliza la redacción del tipo del art. $361.2^{\circ}$ es un elemento que debe ser valorado objetivamente; es suficiente que conforme a las circunstancias concretas en que el hecho ha tenido lugar, sea posible afirmar que el sujeto ex-ante debía haberse representado el estar ejecutando un acto sexual sin el consentimiento del otro. Ninguna importancia tienen las razones previas que han conducido a la disminución significativa de la consciencia, lo importante es que el sujeto activo se aproveche de esa circunstancia objetiva en la que se encuentra la víctima y, en consecuencia, el estado de disminución de capacidades de respuesta puede haber sido creado de modo imprudente por el sujeto pasivo, o bien, por el autor. En tal sentido, el actuar dolosamente supone aquí una indiferencia frente a la prohibición de ejecutar actos sexuales sin el consentimiento de las otras personas ${ }^{39}$.

Ahora bien, esta posibilidad dependerá también de las circunstancias concretas, porque no es lo mismo que alguien se aproveche de una disminución significativa de consciencia en que se encuentra otro, que el caso de quien se emborracha hasta casi perder la consciencia para desinhibirse, o bien, el supuesto de parejas que tienen relaciones sexuales de modo regular y suelen emborracharse o drogarse, en tales casos la posibilidad de valorar la ausencia de consentimiento parece depender de la apreciación probatoria de la existencia de consensos previos de naturaleza genérica ${ }^{40}$.

En estos casos más que pedirse la prueba de una ausencia de acuerdo, que es característica de la fuerza, intimidación y privación total de sentido, en cuanto medios de comisión, es suficiente si se puede afirmar aquí que ha tenido lugar una aquiescencia renuente motivada por ciertas condiciones espacio-temporales que suponen la disminución de las posibilidades de rechazar la realización de un acto sexual. El fundamento de esta afirmación está en que un Derecho penal fundando en la protección plena de la autodeterminación de las personas adultas en el plano sexual, las conductas que suponen la ausencia de acuerdo (absence of agreement) y los hechos que pueden ser interpretados como un ascenso o aquiescencia renuente (reluctant acquiescence $)^{41}$, deben tener el mismo significado valorativo, si es que ambos tienen por origen un abuso, aprovechamiento o disminución de las facultades de decisión en este ámbito ${ }^{42}$. De este modo, para efectos de protección el Derecho no solo reconoce supuestos de ausencia total de consentimiento, sino también casos en que la posibilidad de decidir se encuentra significativamente disminuida.

\footnotetext{
${ }^{39}$ Se trata de un supuesto en que $A$ ha sido indiferente frente a la posibilidad razonable (riesgo substancial) que $B$ no consistiera. Se trata de casos donde el dolo se sitúa en la frontera de la indiferencia consciente sobre las consecuencias futuras del riesgo y la consciencia cierta de los riesgos que conlleva la acción. En el Reino Unido se le trata como un supuesto situado entre el conocimiento y la indiferencia consciente, conforme a la regla de "Cunningham recklessness". LAMB, Jeffrey, Sexual Offences. London: Lexis Nexis UK, 2003, pp. 15-16.

${ }^{40}$ Es evidente que en las relaciones sexuales “esporádicas o casuales” no existen tales consensos previos. Así, ORTS BERENGUER/SUÁREZ-MIRA, "Los delitos”, cit. nota n 17, pp. 126-129.

${ }^{41}$ Fundamental, con referencias a esta distinción, ROOK/WARD, Sexual, cit. nota no 1, pp. 33 y ss.

${ }^{42}$ R. v. Olugboja, Law Reports, Queen's Bench (1982), pp. 320 y ss.
} 
OXMAN, Nicolás. "La incapacidad para oponerse en los delitos de violación y abusos sexuales".

\subsection{Intoxicación por consumo de drogas o alcohol.}

Resulta evidente que esta situación debe ser acogida en los supuestos en que una persona administra a otras substancias con la finalidad de disminuir sus posibilidades de resistencia a la agresión sexual. Este caso no debería revestir mayores inconvenientes ${ }^{43}$. Se trata de abordar la posibilidad de relevancia penal de situaciones donde las personas se ven involucradas en contextos sexuales sin oportunidades de manifestar una voluntad contraria, porque dicha posibilidad se encuentra disminuida considerablemente como consecuencia de una intoxicación por consumo masivo de drogas o alcohol. Ahora bien, es evidente que la incapacidad debe ser grave y, al mismo tiempo, no debe alcanzar a la privación total de sentido porque en ese caso tendría lugar ese medio de comisión.

El criterio de gravedad debe ser valorado objetivamente. Al respecto, algunos ordenamientos aceptan de modo expreso la intoxicación por alcohol o drogas como un supuesto de incapacidad de manifestar el consentimiento en materia sexual ${ }^{44}$. Aquí ninguna prueba sobre la resistencia debería ser requerida, porque debería ser suficiente con una declaración de la víctima que de modo expreso signifique no consentir en el acto sexual. Ahora bien, es evidente que el testimonio debe estar rodeado de un conjunto de hechos que permitan darle la credibilidad suficiente para desvirtuar la presunción de inocencia.

En este sentido, teniendo en cuenta que el punto de partida no es otro que otorgarle el valor preferencial al consentimiento inequívoco, debería ser suficiente con la sola manifestación de una voluntad contraria para poder afirmar que no estaba presente: "no quería del todo", significa, igualmente aquí: "no" 45 . Incluso es más, el silencio no debería ser entendido como aceptación en los casos en que el alcohol o las drogas están presentes, en especial, si del contexto en que ha tenido lugar la relación sexual y de las pruebas adicionales resulta que el hecho puede ser interpretado como un acto en el que el consentimiento no estaba inequívocamente presente, en la medida que pueda entenderse que uno de los partícipes ha asumido el riesgo que el consentimiento no esté presente, si en la situación concreta era factible haberse representado al menos como esta posibilidad como una consecuencia altamente probable dado el contexto de vulnerabilidad en que se hallaba el otro ${ }^{46}$. La pruebas científicas sobre el consumo masivo de alcohol o drogas, pueden ayudar en la medida que, en la actualidad, se sabe que estas substancias producen en algunas personas consecuencias similares a las de una intimidación grave, capaz de producirles miedo o paralizarlas al punto de restringir sus posibilidades de respuesta al ataque, en algunos contextos puede suceder que producto de ese miedo la víctima preste su colaboración a la realización del acto sexual, usualmente en la creencia que esta actitud disminuye las posibilidades de sufrir lesiones en su integridad personal ${ }^{47}$.

\footnotetext{
43 \$231.1 CPM.

${ }^{44}$ Así, en el Reino Unido, CARD, "Sexual”, cit. nota no 1, pp. 31 y 43.

${ }^{45}$ SCHULHOFER, "Taking Sexual”, cit. nota ${ }^{\circ}$ 9, pp. 41 y ss.

${ }^{46}$ LAFAVE, Criminal, cit. nota ${ }^{\text {o } 37, ~ p . ~} 919$.

${ }^{47}$ Ampliamente, FALK, Patricia, "Rape by Drugs: A Statutory Overview and Proposals for Reform", Arizona Law Review Vol. 44 (2002), pp. 131 y ss.
} 
Polít. crim. Vol. 10, No 19 (Julio 2015), Art. 4, pp. 92-118.

[http://www.politicacriminal.cl/Vol_10/n_19/Vol10N19A4.pdf]

En tal sentido, la sola declaración de la víctima debería ser suficiente si ella no está motivada en móviles espurios, es coherente y persistente en la imputación penal (factores esenciales) y, además, existe otra prueba periférica de cargo, especialmente, informes periciales que acrediten la existencia de un estrés postraumático coincidente con la existencia de una agresión sexual, junto a otros elementos que pueden ser tomados en consideración, en concreto, la denominada escala móvil de aproximación ("sliding-scale approach") que ayuda a establecer la credibilidad del testimonio (factores periféricos) ${ }^{48}$.

La escala móvil de aproximación, considera como referencia la cantidad de bebidas alcohólicas ingeridas, el grado de intoxicación, teniendo en cuenta no solo la alcoholemia o el examen toxicológico inmediatamente posterior a la denuncia, sino también otras pruebas adicionales como la medición del nivel individual de tolerancia al alcohol o drogas, lo que depende de otros factores fisiológicos, en especial, los de naturaleza física como el tamaño y peso de la víctima ${ }^{49}$.

Los tribunales chilenos son reticentes a otorgar valor a la alegación de ausencia de consentimiento producto de la ingesta masiva de alcohol o drogas. En la medida que el criterio dominante es el de la no apreciación de la incapacidad para oponerse en estos casos. Así, en supuestos de violación se ha dicho que se trata de un supuesto no abarcado por el tipo legal, en la medida que la intoxicación por ingesta de alcohol no alcanza a la privación total de sentido ${ }^{50}$. Con el mismo argumento, se ha ido más lejos al decir que incluso en supuestos de defectos de constitución física conocidos del sujeto activo, en concreto, diabetes con dependencia a la insulina, a lo que se la unían otras circunstancias como la ausencia de ingesta de alimentos en horas por parte de la presunta víctima y a un estado de embriaguez evidente, no disminuyen la incapacidad de oponerse a la agresión ${ }^{51}$.

En este orden de consideraciones, se ha estimado como insuficiente para poder acreditar una violación la situación de una mujer que alegaba haber estado borracha y drogada y, que en tales circunstancias se "paralizó", por lo que no pudo hacer nada frente a los requerimientos de realización de acciones sexuales por parte dos sujetos, uno de los cuales le puso la mano en la cara para que no gritara, además de accederla carnalmente, declarando la víctima no haber manifestado una oposición decidida, en la medida que indicó haber "aceptado" el acto sexual por miedo a las represalias de los dos sujetos ${ }^{52}$.

Se ha indicado, también, como fundamento del rechazo que en situaciones donde existe consumo excesivo de alcohol falta el "dolo directo", porque "no puede existir un aprovechamiento" $\mathrm{y}$, por ende, estaría también ausente la "finalidad" de acceder a la

\footnotetext{
${ }^{48}$ Esta tesis en KRAMER, Karen, "Rule by Myth: The Social and Legal Dynamics Governing AlcoholRelated Acquaintance Rapes”, Stanford Law Review, vol. 47: 1 (1994), pp. 115-160.

${ }^{49}$ KRAMER, "Rule", cit. nota ${ }^{\circ} 48$, pp. 132 y ss.

${ }^{50}$ En este sentido, confirmando la absolución por atipicidad y falta de prueba de algún medio de comisión legal, la Sentencia Corte de Apelaciones de Copiapó, 06.10.2014, rol no 275-2014.

${ }^{51}$ Sin entrar al fondo de la modificación legal, la Sentencia Corte de Apelaciones de Chillán, 12.09.2014, rol $\mathrm{n}^{\mathrm{o}}$ 234-2014.

52 El Ministerio Público acusó por "uso de fuerza" y el Tribunal absolvió por no haberse acreditado la existencia de "lesiones físicas o genitales". Sentencia Primer Tribunal Oral en lo Penal de Temuco, 31.04.2006, rit n⿳ 13-2006.
} 
OXMAN, Nicolás. "La incapacidad para oponerse en los delitos de violación y abusos sexuales".

víctima "contra su voluntad", en la medida que la oposición no resulta en estos casos "evidente", pese a que conforme a la declaración de la víctima se haya desobedecido su petición de no realización de actos sexuales, en contextos en que se puede haber realización consentida de actos previos de significación sexual, donde la oposición verbal existe, únicamente, en relación al acceso carnal, en la medida que la víctima declara que, en una cadena de acontecimientos donde a raíz de la intoxicación tiene solo recuerdos parciales, se "paralizó", después que el acusado la pusiera "boca abajo a la sobre un sillón, le bajara los pantalones y la penetrara analmente", obviando la petición expresa de detenerse en la medida que "no había consentido verbalmente en el acto sexual, ni pudo oponerse por hallarse ebria",53.

Ahora bien, si encontrar un caso en que se condene es ya una sorpresa, tanto lo es más que lo sea con hechos probados relativamente similares, en la medida que se ha estimado que existen abusos sexuales cometidos con incapacidad de resistir -incluso, con la redacción anterior de la reforma del art. $361.2^{\circ}$ - en el caso de un sujeto que fue acusado de aprovecharse el estado de intoxicación alcohólica en que se encontraba la víctima, al ingresar a su habitación y bajar sus pantalones para tocar con una mano su vagina siendo sorprendido por un tercero con la cabeza de la mujer sobre sus muslos ${ }^{54}$.

No solo asombra la evidente disparidad de criterios, sino también que esta actitud contraste con la aceptación generalizada que se tiene del consumo de drogas y alcohol como un supuesto de incapacidad de oposición por disminución considerable de las facultades de respuesta consciente, en el Derecho comparado ${ }^{55}$. En realidad esto que hasta hace un tiempo era el criterio comúnmente aceptado, está motivado en condicionamientos socioculturales conforme a los cuales no es posible dar lugar a la alegación de ausencia de consentimiento porque el alcohol es una substancia aceptada que está presente en la mayoría de las relaciones sexuales esporádicas o que tienen lugar después de fiestas de fin de semana que, precisamente, son los supuestos en que con mayor regularidad se dan estos $\operatorname{casos}^{56}$. Tal condicionamiento se extendió también por mucho tiempo a las sustancias tóxicas, más aún si están presentes en ambos intervinientes, porque se decía que había una suerte de consentimiento tácito, presunto, sobrevenido o a lo más, eventualmente, se trataba de casos de exceso en el consentimiento ${ }^{57}$.

El Derecho comparado camina por la vía contraria y el nuestro debería seguirle ${ }^{58}$. Así, recientemente, el Tribunal Supremo alemán ha estimado que debe apreciarse incapacidad de resistir y admitirse la imputación a título de abusos sexuales cometidos bajo dicha

\footnotetext{
${ }^{53}$ Este es, precisamente, el caso que se absuelve en la Sentencia del Tribunal Oral Penal de Copiapó, 14.09.2009, rit n ${ }^{\circ}$ 45-2009.

${ }_{55}^{54}$ Véase, Sentencia Corte de Apelaciones de Coyhaique, 28.12.2007, rol n ${ }^{\circ}$ 105-2007.

55 Una comparación resumida entre los sistemas anglosajones y el derecho alemán, puede verse en DUBBER/HÖRNLE, Criminal, cit. nota n ${ }^{\circ} 5$, pp. 614 y ss.

${ }^{56}$ GOODMAN, Christine Chambers, "Protecting the Party Girl: A New Approach for Evaluating Intoxicated Consent", Pepperdine University School of Law Legal Studies Research Paper Series Paper, 13 (2009), pp. 57 y ss.

${ }^{57}$ Ampliamente, POLLOCK, Joycelyn, Criminal Law. Waltham: Elsevier edition, 10a ed. 2013, pp. 211-214.

${ }^{58}$ Véase, por ejemplo, el resumen de la evolución en DRESSLER, Understanding, cit. nota n ${ }^{\circ} 15$, pp. 571 y ss.
} 
Polít. crim. Vol. 10, No 19 (Julio 2015), Art. 4, pp. 92-118.

[http://www.politicacriminal.cl/Vol_10/n_19/Vol10N19A4.pdf]

modalidad, en el caso de un joven que hallándose en el suelo, colapsado por el consumo excesivo de alcohol después de una fiesta de cumpleaños, no se percató totalmente de lo que estaba ocurriendo, ni pudo oponerse decididamente a sus amigos que le introdujeron una botella por el ano para hacer un video y burlarse de él ${ }^{59}$.

Se han indicado aquí criterios probatorios aceptados que permiten trazar la línea divisoria entre la ausencia-presencia de consentimiento en casos en que el consumo de substancias tóxicas está presente. La genérica redacción del tipo del art. $362.2^{\circ}$ no es un argumento para requerir una regla expresa de intoxicación por alcohol o drogas como supuesto de incapacidad como existe en el Derecho comparado, en la medida que, incluso los ordenamientos penales que no la tienen expresamente contemplada, aceptan que en estos casos la aquiescencia renuente tiene el mismo significado, porque supone un aprovechamiento de la disminución de las facultades de decisión que debe ser interpretado como un caso de ausencia de consentimiento.

\subsection{Somnolencia y sueño profundo.}

El sueño profundo y los estados de somnolencia son supuestos evidentes de disminución significativa de las capacidades de respuesta consciente y de oposición a una agresión sexual. Sin embargo, los tribunales se muestran reticentes a la aceptación del sueño profundo como un supuesto de incapacidad psíquica para oponerse ${ }^{60}$. En general, se argumenta que el art. $362.2^{\circ}$ solo comprende estados de desvalimiento o impedimentos físicos, consistentes en estados de vulnerabilidad preexistentes que disminuyen o anulan su posibilidad de defensa $\mathrm{y}$, por ende, se dice que el hecho que una persona se encuentre dormida no puede considerarse como un impedimento de naturaleza equivalente, porque el sueño solo es una sustracción temporal de alerta, que al no ser un padecimiento de orden físico no se encuentra amparado en la norma y, por ende, las situaciones en que se realicen tocamientos que se realizan mientras la víctima está dormida o en un estado de disminución de la conciencia no pueden ser estimados como casos amparados por la norma penal, siendo atípicos ${ }^{61}$, más todavía si consta que la supuesta víctima ha dado una respuesta que no puede ser entendida como una voluntad contraria a la realización de tales acciones, en cuanto las ha tolerado y, en algunos casos, ha manifestado en principio una respuesta que puede ser interpretada como un consentimiento a la realización de acciones de naturaleza sexual.

Conforme a estos argumentos, se ha revocado la sentencia condenatoria que recayó sobre un sujeto que realizó tocamientos a un mujer por debajo de la manta que usaba para cubrirse mientras iba dormida en un autobús urbano; porque no se pudo acreditar una oposición decidida a la realización de dichas acciones y el estado letárgico que se produce como consecuencia del cansancio que desencadena en el sueño no serían supuestos

\footnotetext{
${ }^{59} \mathrm{BGH}, 20.12 .2007$, NStZ - Rechtsprechungsreport Strafrecht (2008), pp. 339 y ss.

${ }^{60}$ Se le reconoce expresamente, por ejemplo, como supuesto de incapacidad psíquica de oposición en el $\$ 75$ (2) (d) Sexual Offences Act 2003, del Reino Unido.

${ }^{61}$ Al respecto y con matices, en la medida que se trataba de un caso donde la prueba de la significación y relevancia necesaria para configurar la acción típica del abuso sexual fue muy difusa, puede verse la Sentencia Cuarto Tribunal Oral en lo Penal de Santiago, 28.10.2011, rit nº 164-2011.
} 
OXMAN, Nicolás. "La incapacidad para oponerse en los delitos de violación y abusos sexuales".

abarcados por la norma, pese a que por la entidad y naturaleza de las acciones habían sido estimadas como relevantes para la estimación de un delito de abuso sexual por parte del tribunal $^{62}$.

La disparidad de criterios se presenta aquí con dos argumentos alternativos: por una parte, se ha dicho que el sueño profundo es un estado de disminución de las capacidades de respuesta abarcado dentro de la privación total de sentido $\mathrm{y}$, por la otra, que el sueño profundo se corresponde con el título de imputación de la incapacidad para oponerse.

En relación con el primer punto de vista, se trata de una tesis que a falta de regulación expresa de la incapacidad para oponerse es compartida por un sector de la doctrina y jurisprudencia españolas. Siguiendo este criterio, se condenó a un padre que ingresó durante la noche a la habitación de su hija mientras dormía, realizándole tocamientos en los senos y en la vagina, sobre la base de la estimación que el sueño imposibilita la posibilidad de evitar y repeler agresiones sexuales, de un modo "equivalente a la privación de sentido como un estado transitorio de pérdida de conciencia donde la víctima se encuentra imposibilitada para recibir las impresiones provenientes del mundo externo"63. En cuanto al segundo punto, se sostiene derechamente que concurre una incapacidad para oponerse en el supuesto de un sujeto que, aprovechándose que la víctima dormía profundamente en un sillón, bajó sus pantalones y ropa interior, tocando con su pene la vagina de la mujer, momento en que ésta despertó ${ }^{64}$.

\subsection{Anomalías y perturbaciones no constitutivas de enajenación o trastornos mentales.}

En esta materia la ley chilena efectúa una doble distinción. Por un lado, protege a todas las personas mayores de catorce años que, padeciendo una enajenación o trastorno mental, vean aún más limitada su capacidad de decisión en el plano sexual, con consecuencia de una ausencia de consentimiento originada en medios abusivos (art. 361.3 ${ }^{\circ}$ ). Y, por otro lado, en cuanto a las personas menores de edad pero mayores de catorce años, esta posibilidad se extiende al abuso de anomalías y perturbaciones que no son constitutivas de enajenación o trastorno, conforme a la regulación del delito de estupro (art. $363.1^{\circ}$ ), porque este tipo penal contempla medios de comisión, por cierto, extensivos a algunas modalidades de abusos sexuales, caracterizados por ser supuestos en los que el consentimiento existe, pero se ha obtenido de un modo viciado, a través del abuso de una posición de prevalencia o engaños.

El hecho que el CP realice esta distinción permite sostener que las acciones sexuales con personas mayores de edad, en el supuesto que sufran de enfermedades o trastornos mentales en sentido amplio, solo adquieren relevancia jurídico-penal si junto con la ausencia de

\footnotetext{
${ }^{62}$ Sentencia de la Corte de Apelaciones de Antofagasta, de 27.05.2011, rol no 124-2011.

${ }^{63}$ Sentencia Corte de Apelaciones de San Miguel, 31.01.2012, rol no 1673-2010.

${ }^{64}$ El fallo plantea otras cuestiones dogmáticas interesantes de las que no puedo hacerme cargo en este lugar, en especial, la discusión sobre el principio de ejecución de la violación y, el problema sobre la diferencia entre la violación tentada y el abuso sexual consumado que, precisamente, es el título de imputación por el cual se condena al acusado en este caso. La sentencia contiene un voto disidente, cuya argumentación gira en torno a la estimación del sueño como un caso abarcado por la incapacidad para oponerse. Sentencia Corte de Apelaciones de Talca, 24.05.2012, rol n 158-2012.
} 
Polít. crim. Vol. 10, No 19 (Julio 2015), Art. 4, pp. 92-118.

[http://www.politicacriminal.cl/Vol_10/n_19/Vol10N19A4.pdf]

consentimiento, en la medida que este ha sido obtenido a través de medios abusivos, la enfermedad o trastorno mental es además grave. En consecuencia, la acciones que consisten en tocamientos corporales con significado sexual o las relaciones sexuales con una persona mayor de edad que sufre de anomalías o trastornos mentales que no alcanzan el concepto de enajenación o trastorno descrito en el medio de comisión del art. $361.3^{\circ}$, no son punibles pese a que el consentimiento pueda ser estimado como inválido, por haber sido obtenido a través de prevalimiento o engaño.

De haberse querido incluir tales casos dentro de la incapacidad para oponerse, el legislador habría tenido que optar por regular de modo conjunto (en un único precepto) las modalidades comisivas del delito de violación y abusos sexuales, sin los márgenes de edad eliminado el delito de estupro dentro del sistema. Por el contrario, el mantener el delito de estupro (art. 363) conlleva una importante consecuencia: la ley distingue entre, por un lado, los estados de diminución de capacidades de oposición que involucran ausencia de consentimiento y, por el otro, los supuestos de limitación de capacidad de oposición que deben ser interpretados como casos de consentimiento viciado. Así, no es lo mismo realizar una conducta de acceso carnal o un acto de significación sexual con ausencia de consentimiento que con el consentimiento viciado del otro interviniente, por ello, la pena del delito de violación de personas mayores de catorce años (art. 361) es mayor que la del delito de estupro (art. 363) y, por lo mismo, el consentimiento viciado de una persona adulta para la realización de las conductas constitutivas de acceso carnal o de actos de significación sexual, son atípicas.

Lo cierto es que nuestros tribunales han planteado otras interpretaciones que pretenden salvar de lege data un aparente defecto de técnica legislativa. En efecto, en el Derecho comparado la tendencia es, como se ha indicado, establecer medios de comisión comunes a todos los atentados a la libertad sexual y, después, graduar la pena en función de otros factores, entre los que aparece la edad y entidad de la conducta sexual que se realiza. Ahora bien, en relación a las citadas hipótesis alternativas de la práctica judicial, es posible distinguir tres: primera, que los casos que no son constitutivos de enajenación o trastorno mental pueden ser entendidos, derechamente, como supuestos de incapacidad para oponerse; segunda, que bajo ningún supuesto los casos de anomalías o perturbaciones mentales que no alcanzan a la enajenación pueden ser considerados como constitutivos de las hipótesis de los numerales $2^{\circ}$ o $3^{\circ}$ del art. 361, porque son atípicos; y, tercera, que una anomalía o perturbación mental incluso no grave puede ser estimada como enajenación si va unida de otras circunstancias que permitan fundamentar un incremento de la imposibilidades de oposición.

La primera y segunda tesis han sido objeto de debate en una sentencia que se encarga de la posibilidad de imputar un abuso sexual contra un joven de veinte años perteneciente a una escuela para personas con retraso mental quien, mientras realizaba junto a su curso una excursión o paseo, concurrió a cambiarse ropa al interior de un autobús, momento en que el chofer le solicitó consentir en practicar una felación oral. El voto de mayoría, que está por la primera de las tesis referidas, entiende que en este caso concurrió un abuso consistente en un aprovechamiento de la situación de desvalimiento del ofendido, en la medida que se encontraba solo con el agresor en la parte trasera del autobús y sin un profesor de la escuela 
OXMAN, Nicolás. "La incapacidad para oponerse en los delitos de violación y abusos sexuales".

que pudiese auxiliarle oportunamente; y, por ende, afirma que la víctima no pudo oponerse dada la evidente disminución de sus facultades mentales, la que habría sido descrita en el peritaje psicológico durante el juicio oral. En contra de esta tesis, el voto de minoría es tajante en apuntar que la incapacidad para resistir (en la redacción anterior), está solo referida a limitaciones de orden físico y, además, que el voto de mayoría ha extendido la aplicación del medio comisivo del art. $361.3^{\circ}$ más allá de lo que permite la ley, en la medida que ha considerado concurrente una hipótesis que es exclusiva del estupro y abusos sexuales cometidos con la circunstancia $1^{\circ}$ del art. 363 que, por cierto, solo resulta aplicable a los trastornos de menor entidad en los que el sujeto pasivo sea mayor de catorce pero menor de dieciocho años ${ }^{65}$.

De la tercera posibilidad se hace cargo un fallo en el que se estima que la presencia de una enajenación mental del art. $361.3^{\circ}$ y no del art. $363.1^{\circ}$, respecto del acceso carnal realizado con una persona de catorce años que padecía de una discapacidad mental moderada (eventualmente abarcada por el art. $363.1^{\circ}$ ), a lo que se unió el consumo excesivo de alcohol que habría disminuido sus posibilidades de oposición ${ }^{66}$.

Para evitar la desprotección de personas que sufren alternaciones mentales que no alcanzan a constituir una enajenación o trastorno grave, en el Derecho comparado se ha extendido expresamente la posibilidad de abarcar todo tipo de enfermedades o trastornos psicológicos, incluso sin limitaciones relativas a la intensidad de estos o a la edad del sujeto pasivo, con la única exigencia que conforme a las circunstancias concretas tal situación implique una disminución significativa de la capacidad de respuesta psicológica y una susceptibilidad de instrumentalización en el ejercicio de la sexualidad, de la cual se prevale el autor ${ }^{67}$.

\subsection{Acerca del llamado síndrome de acomodación a la agresión sexual.}

Un sector de la doctrina ${ }^{68}$, amparándose en la nueva redacción, se muestra partidaria de considerar el denominado "síndrome de acomodación a las agresiones sexuales" como una forma de incapacidad de oposición. La cuestión tiene su origen en un debate jurisdiccional que, con argumentos variados, se inclina por el rechazo tanto de la posibilidad de entender que este "síndrome" es subsumible en la incapacidad psíquica como de la hipótesis alternativa que aboga por admitir algún tipo de intimidación ${ }^{69}$.

\footnotetext{
${ }^{65}$ Sentencia Tercer Tribunal Oral en lo Penal de Santiago, 07.08.2006, rit no 141-2006. También, se refiere a la posibilidad de estimar una incapacidad para oponerse en casos de víctimas que sufren un trastorno mental no constitutivo de enajenación (art. 361.3º la Sentencia Corte de Apelaciones de Temuco, 27.01.2012, rol $\mathrm{n}^{\circ} 12-2012$.

${ }^{66}$ Sentencia Tribunal de Juicio Oral en lo Penal de Cauquenes, 12.07.2013, rit no 44-2013.

${ }^{67}$ Así, en el derecho alemán conforme explica LAUBENTHAL, Handbuch, cit. nota no 1, pp. 55-124 y 169 y Ss.

${ }^{68}$ SANTIBÁÑNZ, “Delimitación”, cit. nota n 11, p. 57. También, BALMACEDA, Manual, cit. nota n 11, p. 219.

${ }^{69}$ Por ejemplo, acoge el recurso de nulidad y absuelve por estimar que no concurre ni siquiera intimidación en el supuesto de una víctima mayor de edad que reconoció haber consentido la realización de actos sexuales con su padre, por el temor fundando de ser goleada, conducta recurrente del agresor durante su infancia, la Sentencia Corte de Apelaciones de Talca, de 17.08.2011, rol n ${ }^{\circ}$ 280/2011. Al respecto, la Corte Suprema entiende que la intimidación es "el temor de sufrir el mal debe ser serio, grave y efectivo basado en actos
} 
Polít. crim. Vol. 10, Nº 19 (Julio 2015), Art. 4, pp. 92-118.

[http://www.politicacriminal.cl/Vol_10/n_19/Vol10N19A4.pdf]

Al respecto, en relación con este "síndrome" habría que indicar algunas objeciones que pesan contra su admisibilidad en la descripción de estados psicológicos subsumibles en el supuesto de incapacidad para oponerse de los delitos de violación y abusos sexuales cometidos contra personas adultas. En efecto, sucede que el referido "síndrome" fue pensado para describir una sintomatología asociada a abusos sexuales cometidos contra personas menores de $\operatorname{edad}^{70}$, con una metodología diferenciada que no es aplicable a los adultos, además, en la actualidad se han extendido en Estados Unidos posturas que lo desacreditan como una pericia científica válida para la reconstrucción del relato de abuso sexual de menores ${ }^{71}$. Sin embargo, para las personas adultas se han descrito otras formas concretas de desórdenes o trastornos psicológicos originados, en especial, en un trastorno asociado al estrés postraumático denominado síndrome de la persona maltratada (battered person syndrome $)^{72}$, el cual explica la sintomatología que manifiestan las personas que han sufrido una exposición prolongada y directa a la violencia, caracterizada porque se desencadena una condición mental y física que se expresa en la experimentación constante y recurrente del maltrato, en la evitación de las relaciones personales y sociales, hipersensibilidad, distorsión de la imagen corporal y otras manifestaciones somáticas, como dificultades para expresar una sexualidad e intimidad adecuadas.

Es evidente que el Derecho penal debe estimar con relevancia típica los estados emocionales que, sin implicar una disminución absoluta de la capacidad de oposición, pueden ser interpretados como una ausencia de consentimiento. En estos supuestos, la víctima accede a la realización de acciones sexuales debido al padecimiento de un miedo intenso originado en el maltrato físico y/o psicológico prolongado que ha sido infligido, precisamente por quien se aprovecha de este estado para involucrarle en un contexto sexual. La tesis aquí defendida, conforme a la cual la incapacidad psíquica de oposición es un supuesto limitado a disminuciones significativas de la consciencia que no alcanzan a la privación de sentido, impide considerar casos de aprovechamiento e instrumentalización de otro fundado en el miedo que a la víctima le produce el agresor. Sin embargo, ello no impide que este estado psicológico pueda ser incluido en otra modalidad de comisión, en concreto, en la intimidación. Con todo, para que pueda darse esta posibilidad, cuestión que excede el objeto de este trabajo, es necesario repensar el concepto de intimidación en los delitos contra la libertad sexual, apartando la idea de que la relevancia típica está dada en una conducta realizada contra la voluntad del sujeto pasivo para entender que se trata de un

concretos de amenaza hacia la integridad de la víctima", Sentencia Corte Suprema, 10.04.2003, rol n 41152002.

${ }^{70}$ El síndrome fue descrito por su autor como un "modelo simple y lógico" para mejorar la comprensión y aceptación de la posición del niño en las dinámicas complejas que involucra la victimización sexual. Se trataría de un proceso de cinco etapas: (1) secreto; (2) impotencia; (3) entrampamiento y acomodación; (4) retraimiento y divulgación poco convincente; y, (5) retractación en el relato. SUMMIT, Roland, "The child sexual abuse accommodation syndrome", Child Abuse and Neglect, 7 (1983), pp. 177-193.

71 En particular, a partir de: ASKOWITZ, Lisa; GRAHAM, Michael, "The Reliability of Expert Psychological Testimony in Child Sexual Abuse Prosecutions”, Cardozo Law Review, 15; 6 (1994), pp. 20272102.

${ }^{72}$ Se explica en especial en relación las mujeres maltratadas en contextos más amplios que los delitos sexuales, FOLLINGSTAD, Diane, "Battered Woman Syndrome in the Courts", en: WEINER, Irving (Ed.), Handbook of Psychology, Forensic Psychology. New Jersey: Ed. Wiley \& Sons, 2003, pp. 485 y ss. 
OXMAN, Nicolás. "La incapacidad para oponerse en los delitos de violación y abusos sexuales".

supuesto en que la acción sexual se ejecuta sin la voluntad de otro, es decir, como un caso más de ausencia de su consentimiento.

\section{Conclusiones.}

En este trabajo se han expuesto los fundamentos dogmáticos sobre los cuales puede reconstruirse el límite de la nueva modalidad de incapacidad para oponerse en los delitos de violación y abusos sexuales. Conforme se ha expuesto, este medio de comisión comprende tanto los padecimientos físicos corporales que impiden prestar una oposición (incapacidad física para oponerse), como también, el aprovechamiento de situaciones en las que se padece una alteración significativa de la posibilidad de percepción del mundo circundante que no alcanzan a la privación total de sentido, en particular, los supuestos en los cuales el sujeto pasivo se encuentra bajo los efectos del alcohol, drogas y el sueño; en concreto, casos en los que existe una disminución relevante de la capacidad de respuesta consciente a las agresiones sexuales (incapacidad psíquica para oponerse).

Esta afirmación es contraria a la tesis que pretende incluir aquí trastornos mentales de menor entidad que no alcanzan a la enajenación, o bien, los supuestos en los que existe el llamado "síndrome de acomodación al abuso".

Ahora bien, la inclusión de comportamientos de prevalimiento o abuso de superioridad y disminución de capacidades psíquicas de la víctima - en lo que al Derecho penal sexual de adultos se refiere- debería ser una cuestión necesaria de lege ferenda. Tal necesidad no puede servir para desnaturalizar de lege data la esencia de las modalidades típicas del art. 361, abarcando casos en que una persona es subordinada por una situación de dependencia con respecto al agresor por alguna circunstancia como la existencia de un entorno intimidatorio, hostil, degradante, o bien, supuestos de aprovechamiento de situaciones de vulnerabilidad, dependencia económica, afectiva o psicológica, a consecuencia de adicciones, embarazos, trastornos de la personalidad, enfermedades mentales que no alcanzan a un limitación absoluta de la capacidad de compresión del entorno, como del sentido o contenido de los actos sexuales. 
Polít. crim. Vol. 10, Nº 19 (Julio 2015), Art. 4, pp. 92-118.

[http://www.politicacriminal.cl/Vol_10/n_19/Vol10N19A4.pdf]

\section{BIBLIOGRAFÍA}

AAVV., Inzestverbot, Berlin: Deutscher Ethikrat, 2014.

AAVV., Model Penal Code. Official Draft and Explanatory Notes, The American Law Institute at Washington, D.C. Philadelphia, 1962. Washington: Ed. Library of Congress, 1985.

AGUILAR, Cristian, Delitos sexuales. Tráfico ilícito de migrantes y trata de personas con fines de prostitución y explotación. Grooming, doctrina y jurisprudencia. Santiago: Ed. Metropolitana, $2^{\mathrm{a}}$ ed., 2012.

ASKOWITZ, Lisa; GRAHAM, Michael, "The Reliability of Expert Psychological Testimony in Child Sexual Abuse Prosecutions", Cardozo Law Review, v. 15; 6 (1994).

BALMACEDA, Gustavo, Manual de Derecho Penal. Parte especial. Santiago: Ed. Librotecnia, 2014.

BASCUÑÁN, Antonio, "La prohibición penal de la homosexualidad masculina juvenil (comentario a la Sentencia del Tribunal Constitucional, 04.01. 2011, rol $\mathrm{n}^{\mathbf{0}} 163$ 2010)", Estudios Públicos, 124 (2011).

"Problemas básicos de los delitos sexuales", Revista de Derecho Universidad Austral de Chile, número especial (1997).

BULlEMORE, Vivian; MACKINNON, John, Curso de Derecho Penal. Parte Especial, t. III, Santiago: Ed. Legal Publishing, $3^{\text {a }}$ ed., 2011.

CADOPPI, Alberto; CANESTRARI, Stefano; MANNA, Adelmo; PAPA, Michele, Trattato di Diritto Penale. Parte Speciale, t. IX, Torino: Ed. Utet-Giuridica, 2011.

CARD, Richard, Sexual Offences: the new law. Bristol: Jordans, 2004.

CARMONA SALGADO, Concepción, El delito de abusos deshonestos. Barcelona: Ed. Bosch, 1981.

COX, Juan Pablo, Los abusos sexuales, Santiago: Ed. Lexis Nexis, 2003.

CRESPI, Alberto; ZUCCALA, Guiseppe; FORTI, Gabrio, Commentario Breve al Codice Penale. Milán: Ed. Cedam, 12 ed., 2011.

DÍEZ RIPOLLÉS, José Luis, "El objeto de protección en el nuevo derecho penal sexual", Revista de Derecho Penal y Criminología, $2^{\mathrm{a}}$ época, 6 (2000).

DRESSLER, Joshua, Understanding Criminal Law. San Francisco: Ed. Lexis Nexis, $6^{\mathbf{a}}$ ed., 2012.

DUBBER, Markus; HÖRNLE, Tatjna, Criminal Law. A Comparative Approach, Oxford: Oxford University Press, 2014.

FALK, Patricia, "Rape by Drugs: A Statutory Overview and Proposals for Reform", Arizona Law Review, 44 (2002).

FIANDACA, Giovanni; MUSCO, Enzo, Diritto penale. Parte speciale, I delitti contra la persona, vol. I., t. I. Bologna: Zanichelli Editore, 5a ed., 2013.

FOLLINGSTAD, Diane, "Battered Woman Syndrome in the Courts", en: WEINER, Irving (Ed.), Handbook of Psychology, Forensic Psychology, New Jersey: Ed. Wiley \& Sons, 2003.

GALLEGO, Javier, "El problema del moralismo legal en el Derecho Penal", Revista de Estudios de la Justicia, 14 (2011).

GARRIDO MONTT, Mario, Derecho Penal. Parte especial, t. III. Santiago: Ed. Jurídica de Chile, $4^{\mathrm{a}}$ ed., 2010. 
OXMAN, Nicolás. "La incapacidad para oponerse en los delitos de violación y abusos sexuales".

GIMBERNAT ORDEIG, Enrique, "Sobre algunos aspectos del delito de violación en el Código Penal español, con especial referencia a la violación intimidatoria”, en: EL MISMO, Estudios de Derecho Penal. Madrid: Tecnos, 1990.

GONZÁLEZ CUSSAC, José Luis, "La contrarreforma penal de 2003: nueva y vieja política criminal”, Revista Jurídica Gallega, 38 (2003).

GOODMAN, Christine Chambers, "Protecting the Party Girl: A New Approach for Evaluating Intoxicated Consent", Pepperdine University School of Law Legal Studies Research Paper Series Paper, 13 (2009).

GÖSSEL, Karl-Heinz, Das neue Sexualstrafrecht. Eine systematische Darstellung für die Praxis. Berlin: De Gruyter Recht, 2005.

GUZMÁN DALBORA, José Luis, “Apreciación y Reprobación de los delitos contra la honestidad en Chile", Anuario de la Facultad de Derecho de la Universidad de Antofagasta, 6 (2000).

KINDHÄUSER, Urs, Strafgesetzbuch. Lehr - und Praxiskommentar, 6. Auflage, BadenBaden: Nomos, 2015.

KRAMER, Karen, "Rule by Myth: The Social and Legal Dynamics Governing AlcoholRelated Acquaintance Rapes", Stanford Law Review, vol. 47: 1 (1994).

LAFAVE, Wayne, Criminal Law. St. Paul: Thomson Reuters, $5^{\text {a }}$ ed., 2010.

LAMB, Jeffrey, Sexual Offences, Lexis Nexis UK, London, 2003

LAUBENTHAL, Klaus, Handbuch Sexualstraftaten. Die Delikte gegen die sexuelle Selbstbestimmung. Berlin: Springer, 2012. , Sexualstraftaten. Die Delikte gegen die sexuelle Selbstbestimmung. Berlin: Springer-Verlag, 2000.

LÓPEZ BARJA DE QUIROGA, Jacobo; RODRÍGUEZ RAMOS, Luis, et al., Códigos Penales españoles. Madrid: Ed. Akal, 1988.

MALDONADO, Francisco, "Delitos contra la libertad sexual. Tratamiento de la nueva regulación de los delitos sexuales", en: AAVV., Problemas Actuales del Derecho Penal. Temuco: Universidad de Temuco, 2003.

MATUS, Jean Pierre; RAMÍREZ, María Cecilia, Lecciones de Derecho Penal chileno. Parte especial, t. I. Santiago: Ed. Legal Publishing-Thomson Reuters, $3^{\text {a }}$ ed., 2014.

ORTS BERENGUER, Enrique, "Delitos contra la libertad e indemnidad sexuales (I)", en: VIVES ANTÓN, Tomás; GONZÁLEZ CUSSAC, José Luis; CARBONELL MATEU, Juan Carlos, et. al., Derecho penal. Parte especial. Valencia: Ed. Tirant lo Blanch, $3^{\mathrm{a}}$ ed., 2010.

, Delitos contra la libertad sexual. Valencia: Ed. Tirant lo Blanch, 1995.

ORTS BERENGUER, Enrique; SUÁREZ-MIRA RODRÍGUEZ, Carlos, Los delitos contra la libertad e indemnidad sexuales. Valencia: Tirant lo Blanch, 2001.

OXMAN, Nicolás, "Una aproximación al sistema de imputación subjetiva en el derecho penal anglosajón”, Ius et Praxis, 19 (2013).

Libertad Sexual y Estado de Derecho en Chile. Las fronteras del Derecho Penal sexual. Santiago: Librotecnia, 2007.

POLITOFF, Sergio; MATUS, Jean Pierre; RAMÍREZ, Ma. Cecilia, Lecciones de Derecho Penal. Parte Especial. Santiago: Ed. Jurídica de Chile, $2^{\mathrm{a}}$ ed., 2005.

POLLOCK, Joycelyn, Criminal Law. Waltham: Elsevier edition, 10a ed., 2013.

PULITANÒ, Domenico, Diritto Penale. Parte speciale: tutela penale della persona, t. I. Torino: Ed. G. Giappicheli Editore, 2ª ed., 2014. 
Polít. crim. Vol. 10, No 19 (Julio 2015), Art. 4, pp. 92-118.

[http://www.politicacriminal.cl/Vol_10/n_19/Vol10N19A4.pdf]

RAMÓN RIBAS, Eduardo, "La reforma de los delitos contra la libertad e indemnidad sexual”, en: ÁLVAREZ GARCÍA (Coord.), Libro Homenaje a Rodríguez Ramos. Valencia: Tirant lo Blanch, 2013.

ROBINSON, Paul; CAHILL, Michael, Criminal Law. Estados Unidos: Wolters Kluwer Law \& Business, 2014.

RODRÍGUEZ COLLAO, Luis, Delitos sexuales. Santiago: Ed. Jurídica de Chile, 2004, y $2^{\mathrm{a}}$ edición, 2014.

ROOK, Peter; WARD Robert, Sexual Offences. Law \& Practice. London: Ed. Sweet \& Maxwell, 2014.

SANTIBÁÑEZ, Magdalena, "Delimitación de la modalidad típica de aprovechamiento de la incapacidad para oponerse en el delito de violación", Doctrina y Jurisprudencia Penal, Universidad de los Andes, 15 (2013).

SANTIBÁÑEZ, Magdalena; VARGAS, Tatiana, "Reflexiones en torno a las modificaciones para sancionar el femicidio y otras reformas relacionadas (Ley 20.480)", Revista Chilena de Derecho, 38; 1 (2011).

SCHÖNKE, Adolf; SCHRÖDER, Horst, Strafgesetzbuch Kommentar, $28^{\mathrm{a}}$ Auflage. München: Verlag C.H. Beck, 2010.

SCHULHOFER, Stephen, "Taking Sexual Autonomy Seriously: Rape Law and Beyond", Law and Philosophy, 11 (1992).

SUMMIT, Roland, "The child sexual abuse accommodation syndrome", Child Abuse and Neglect, 7 (1983).

\section{Documentos}

Historia de la Ley $\mathrm{N}^{\circ}$ 19.617, Biblioteca del Congreso Nacional de Chile, p. 217, disponible en: http://www.leychile.cl/Navegar?idNorma=138814 [consultado el 12.10.2014].

Historia de la Ley $\mathrm{N}^{\circ}$ 20.480, Biblioteca del Congreso Nacional de Chile, disponible en: http://www.bcn.cl/obtienearchivo?id=recursoslegales/10221.3/27994/1/HL20480.pdf [consultado el 09.09.2014].

Mensaje $\mathrm{n}^{\circ}$ 435-361, de 10.04.2014, que contemplaba el Proyecto de Ley de Nuevo Código Penal.

\section{Jurisprudencia}

\section{$\underline{\text { Alemania }}$}

Bundesgerichtshof (BGH), 17.4.2007, NStZ - Neue Zeitschrift für Strafrecht (2007). Bundesgerichtshof (BGH), 20.12.2007, NStZ Rechtsprechungsreport Strafrecht (2008).

Bundesverfassungsgericht (BVerfGe) 120, 224-248, NJW-Neu Juristische Wochenschrift, 4 (2013).

\section{$\underline{\text { Chile }}$}

Sentencia Corte Suprema, 10.04.2003, rol no 4115-2002.

Sentencia Primer Tribunal Oral en lo Penal de Temuco, 31.04.2006, rit no 13-2006.

Sentencia Tercer Tribunal Oral en lo Penal de Santiago, 07.08.2006, rit n⿳0 141-2006. 
OXMAN, Nicolás. "La incapacidad para oponerse en los delitos de violación y abusos sexuales".

Sentencia Corte de Apelaciones de Coyhaique, 28.12.2007, rol nº 105-2007.

Sentencia del Tribunal Oral Penal de Copiapó, 14.09.2009, rit nº 45-2009.

Sentencia Corte de Apelaciones de Temuco, 07.12.2010, rol n $885-2010$.

Sentencia Corte de Apelaciones de San Miguel, 31.01.2012, rol n ${ }^{\circ}$ 1673-2010.

Sentencia Corte de Apelaciones de Talca, de 17.08.2011, rol no 280/2011.

Sentencia de la Corte de Apelaciones de Antofagasta, de 27.05.2011, rol n ${ }^{\circ}$ 124-2011.

Sentencia Cuarto Tribunal Oral en lo Penal de Santiago, 28.10.2011, rit n ${ }^{\circ}$ 164-2011.

Sentencia Corte de Apelaciones de Temuco, 27.01.2012, rol nº12/2012.

Sentencia Corte de Apelaciones de Talca, 24.05.2012, rol nº 158-2012.

Sentencia Tribunal de Juicio Oral en lo Penal de Cauquenes, 12.07.2013, rit no 44-2013.

Sentencia Corte de Apelaciones de Chillán, 12.09.2014, rol n 234-2014.

Sentencia Corte de Apelaciones de Copiapó, 06.10.2014, rol nº 275-2014.

\section{$\underline{\text { España }}$}

Sentencia del Tribunal Supremo, 25.09.2013, $\mathrm{n}^{\circ}$ recurso: 10426-2013, $\mathrm{n}^{\circ}$ resolución: 767/2013, ponente: Manuel Marchena Gómez.

\section{Estados Unidos}

State of Maryland v. Edward Salvatore, Atlantic Reporter, 2d. 424 (1981).

\section{$\underline{\text { Italia }}$}

Corte Cassazione Penale, Sezione. III, 09.06.2004, nº 25727.

\section{$\underline{\text { Reino Unido }}$}

R. v. Olugboja, Law Reports, Queen's Bench (1982). 